Marquette University

e-Publications@Marquette

$12-21-2016$

Energy Gap between the Poly-p-phenylene Bridge and Donor Groups Controls the Hole Delocalization in Donor-Bridge-Donor Wires

Denan Wang

Marquette University, denan.wang@marquette.edu

Marat R. Talipov

Marquette University

Maxim Vadimovich Ivanov

Marquette University

Rajendra Rathore

Marquette University

Accepted version. Journal of the American Chemical Society, Vol. 138, No. 50 (December 21, 2016): 16337-16344. DOI. (C) 2016 American Chemical Society. Used with permission. 


\title{
Energy Gap between the Poly-p- phenylene Bridge and Donor Groups Controls the Hole Delocalization in Donor-Bridge-Donor Wires
}

\author{
Denan Wang \\ Department of Chemistry, Marquette University, \\ Milwaukee, WI \\ Marat R. Talipov \\ Department of Chemistry, Marquette University, \\ Milwaukee, WI \\ Maxim V. Ivanov \\ Department of Chemistry, Marquette University, \\ Milwaukee, WI \\ Rajendra Rathore \\ Department of Chemistry, Marquette University, \\ Milwaukee, WI
}




\section{Abstract}
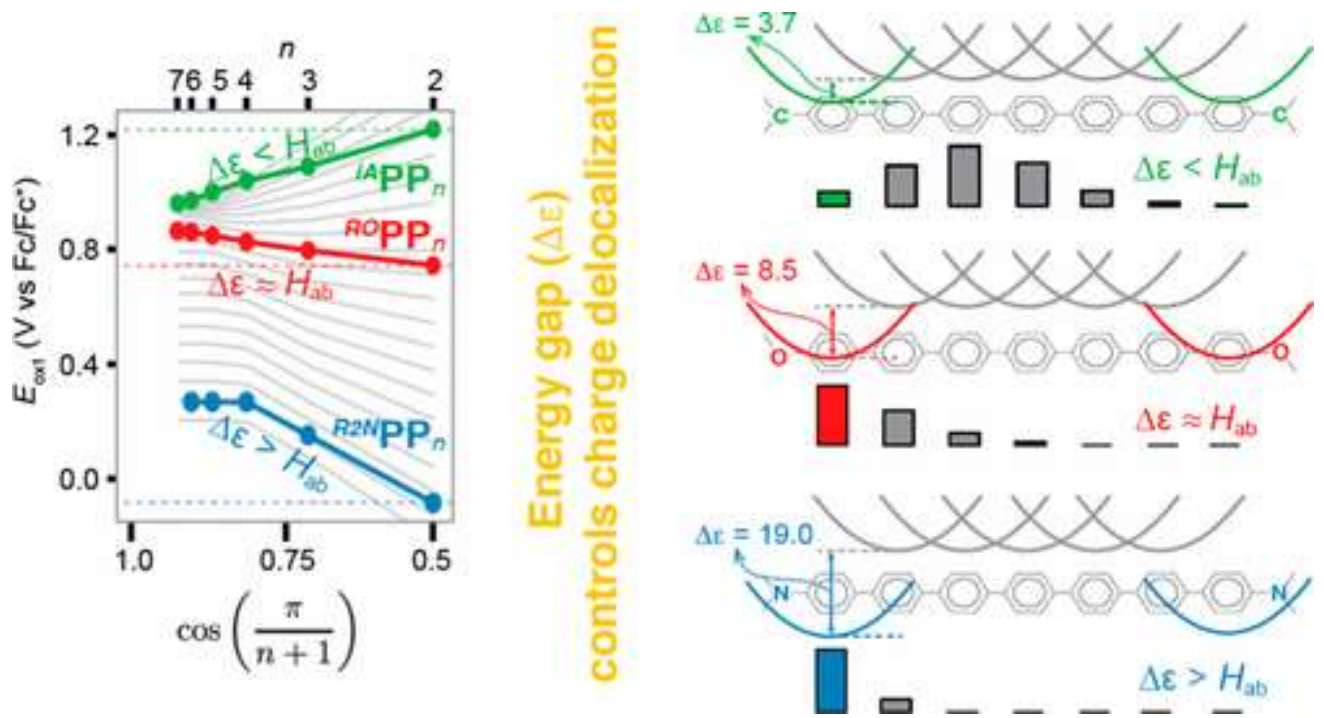

Poly- $p$-phenylene wires are critically important as charge-transfer materials in photovoltaics. A comparative analysis of a series of poly- $p$-phenylene $\left({ }^{\boldsymbol{R}} \mathbf{P} \mathbf{P}_{\boldsymbol{n}}\right)$ wires, capped with isoalkyl ( $\left.{ }^{i} \mathbf{P} \mathbf{P}_{\boldsymbol{n}}\right)$, alkoxy ( $\left.{ }^{\boldsymbol{R O}} \mathbf{P} \mathbf{P}_{\boldsymbol{n}}\right)$, and dialkylamino $\left({ }^{\mathbf{R} 2} \mathbf{P} \mathbf{P} \mathbf{P}_{\boldsymbol{n}}\right)$ groups, shows unexpected evolution of oxidation potentials, i.e., decrease $(-260 \mathrm{mV})$ for ${ }^{i \boldsymbol{A}} \mathbf{P} \mathbf{P}_{\boldsymbol{n}}$, while increase for ${ }^{\boldsymbol{R}} \mathbf{P P P}_{\boldsymbol{n}}(+100 \mathrm{mV})$ and ${ }^{\mathbf{R} \mathbf{N}} \mathbf{P P}_{\boldsymbol{n}}(+350$ $\mathrm{mV}$ ) with increasing number of $p$-phenylenes. Moreover, redox/optical properties and DFT calculations of ${ }^{\mathbf{R} 2} \mathbf{P} \mathbf{P}_{\boldsymbol{n}} /{ }^{\mathbf{R} 2 \boldsymbol{N}} \mathbf{P P}_{\boldsymbol{n}}{ }^{+\bullet}$ further show that the symmetric bell-shaped hole distribution distorts and shifts toward one end of the molecule with only $4 p$-phenylenes in $\boldsymbol{R}^{2} \boldsymbol{N} \mathbf{P P}_{\boldsymbol{n}}{ }^{+}$, while shifting of the hole occurs with 6 and $8 p$-phenylenes in ${ }^{\boldsymbol{R}} \mathbf{O} \mathbf{P} \mathbf{P}_{\boldsymbol{n}}{ }^{+\bullet}$ and ${ }^{i A} \mathbf{P} \mathbf{P}_{n^{+}}$, respectively. Availability of accurate experimental data on highly electron-rich dialkylamino-capped ${ }^{\mathbf{R} 2} \mathbf{P} \mathbf{P P}_{\boldsymbol{n}}$ together with ${ }^{\boldsymbol{R} O} \mathbf{P} \mathbf{P}_{\boldsymbol{n}}$ and ${ }^{\boldsymbol{i} \boldsymbol{A}} \mathbf{P} \mathbf{P}_{\boldsymbol{n}}$ allowed us to demonstrate, using our recently developed Marcus-based multistate model (MSM), that an increase of oxidation potentials in ${ }^{\mathbf{R} 2 \mathbf{N}} \mathbf{P} \mathbf{P}_{\boldsymbol{n}}$ arises due to an interplay between the electronic coupling $\left(H_{\mathrm{ab}}\right)$ and energy difference between the end-capped groups and bridging phenylenes $(\Delta \varepsilon)$. A comparison of the three series of $\boldsymbol{R}_{\mathbf{P P}}$ with varied $\Delta \varepsilon$ further demonstrates that decrease/increase/no change in oxidation energies of $\boldsymbol{R}_{\mathbf{P P}}$ can be predicted based on the energy gap $\Delta \varepsilon$ and coupling $H_{a b}$, i.e., decrease if $\Delta \varepsilon<H_{a b}$ (i.e., ${ }^{i A} \mathbf{P P}_{\boldsymbol{n}}$ ), increase if $\Delta \varepsilon>H_{\mathrm{ab}}$ (i.e., ${ }^{\boldsymbol{R 2 N}} \mathbf{P} \mathbf{P}_{\boldsymbol{n}}$ ), and minimal change if $\Delta \varepsilon \approx H_{\mathrm{ab}}$ (i.e., ${ }^{R O} \mathbf{P P}_{\boldsymbol{n}}$ ). MSM also reproduces the switching of the nature of electronic transition in higher homologues of $\boldsymbol{R}^{\mathbf{2 N}} \mathbf{P} \mathbf{P}_{\boldsymbol{n}}{ }^{+\bullet}(n \geq 4)$. These findings will aid in the development of improved models for charge-transfer dynamics in donorbridge-acceptor systems. 
NOT THE PUBLISHED VERSION; this is the author's final, peer-reviewed manuscript. The published version may be accessed by following the link in the citation at the bottom of the page.

\section{Introduction}

Development of efficient $n$-conjugated molecular wires for longrange charge transfer remains a highly sought goal for photovoltaics and molecular electronics applications. ${ }^{1-5}$ To this end, the identification of the parameters influencing charge delocalization in para-phenylenebased molecular wires is critically important for the guided design of efficient charge-transfer materials for modern applications. Recently, we showed that a single positive charge (i.e., hole) in long $(n>7)$ poly- $p$-phenylene wires $\left(\mathbf{P P}_{\boldsymbol{n}}\right)$ delocalizes only onto seven $p$-phenylene units and lies in the center of the $n$-conjugated chain (Figure 1), owing to the interplay between the energetic gain from charge delocalization and concomitant energetic penalty from the structural/solvent reorganization. ${ }^{6}$ Furthermore, in end-capped poly- $p$-phenylene wires $\left({ }^{\boldsymbol{R}} \mathbf{P}_{\boldsymbol{n}}\right)$ with electron-donating substituents (i.e., $\boldsymbol{R}=\boldsymbol{i \boldsymbol { A }}$ or $\left.\boldsymbol{R O}\right)$, the hole is observed to gravitate toward one end of the molecule to make use of the electron-donating terminal units for hole stabilization (Figure 1). The observed displacement of the hole toward one end in $\boldsymbol{R P P}_{\boldsymbol{n}}$ and its consequences to the redox and optical properties were reproduced by a versatile Marcus-based multistate parabolic model (MPM), where energies of the substituted terminal units with respect to bridging $p$-phenylenes were lowered (by $\Delta \varepsilon$ ), while the coupling $\left(H_{\mathrm{ab}}\right)$ and the reorganization parameter $\lambda$ were kept constant for all ${ }^{\boldsymbol{R}} \mathbf{P P}_{\boldsymbol{n}}$, where $\boldsymbol{R}=\boldsymbol{H}, \boldsymbol{i A}, \boldsymbol{R O}$ (Figure 1 , bottom). ${ }^{6}$ 


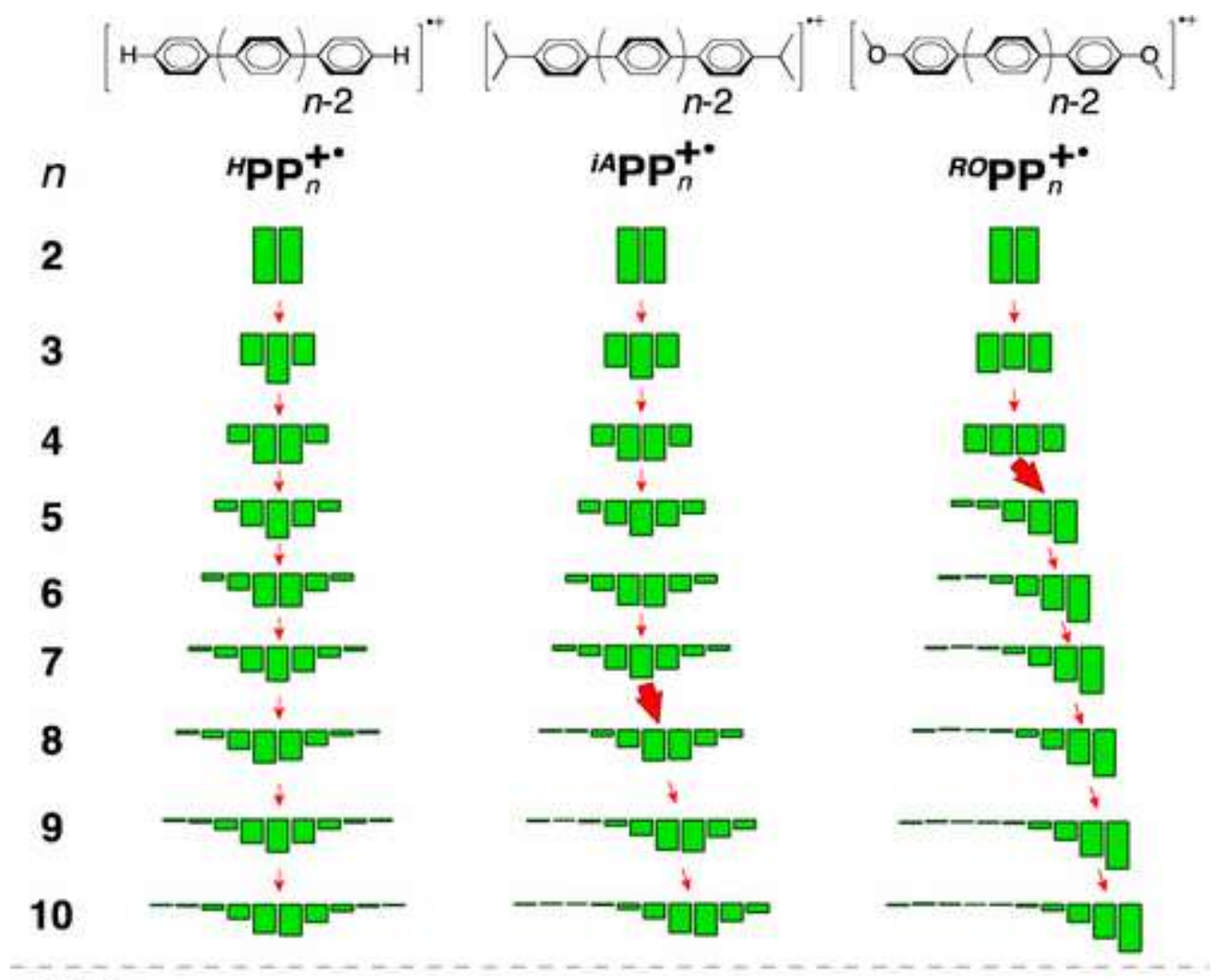

MSM:

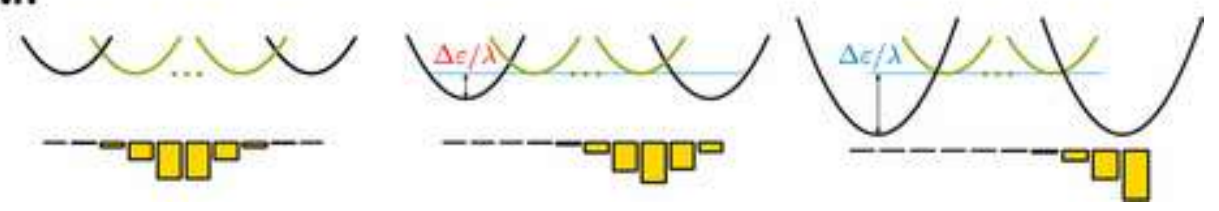

Figure 1. Per-unit hole distribution in various poly- $p$-phenylene wires (as indicated) [B1LYP-40/6-31G(d)+PCM $\left.\left(\mathrm{CH}_{2} \mathrm{Cl}_{2}\right)\right]$ and the corresponding hole distribution bar plots reproduced by the MSM (bottom panel). ${ }^{6}$

A curious finding of this work was that, while the oxidation potentials of isoalkyl-capped ${ }^{\mathbf{A}} \mathbf{P P}_{\boldsymbol{n}}$ showed an expected decrease with increasing number of $p$-phenylene units $(n)$, the alkoxy-capped ${ }^{\boldsymbol{R O}} \mathbf{P P}_{\boldsymbol{n}}$ showed a modest increase with $n$. In order to examine this further, in this study we investigate redox and optoelectronic properties of poly$p$-phenylene wires capped with highly electron-rich $N, N$ diisopropylamino substituents (i.e., ${ }^{\mathbf{R} 2 N} \mathbf{P P}_{\boldsymbol{n}}$ ). A cursory examination of ${ }_{\text {R2NPP }}$ using our MPM with identical parameter $H_{a b} / \lambda$ and the one variable parameter $\Delta \varepsilon$, which was significantly larger for ${ }^{\mathbf{R} 2 N} \mathbf{P P}_{\boldsymbol{n}}$ (Figure 2) in comparison to other ${ }^{\mathbf{R}} \mathbf{P P}_{\boldsymbol{n}}$, indicated that the hole is shifted toward one end of the wire with just two bridging $p$-phenylene units (i.e., ${ }^{\mathbf{R} N} \mathbf{P P}_{4}{ }^{+\bullet}$ ). 


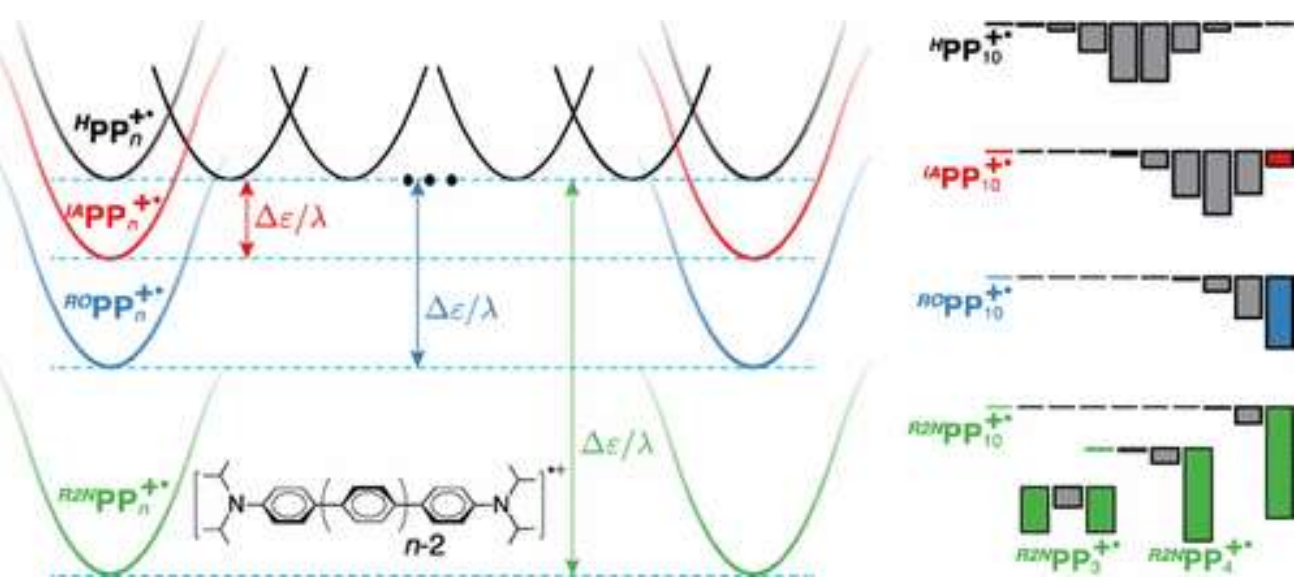

Figure 2. Graphical depiction of the MSM applied to dialkylamino-capped poly- $p$ phenylenes and comparison with other $\boldsymbol{R}_{\mathbf{P}} \mathbf{P}_{\boldsymbol{n}}$ cation radicals.

In order to provide a detailed picture of the critical role of the energy gap between the terminal and bridging $p$-phenylene units on the extent of hole distribution and evolution of oxidation energies, ${ }^{7-11}$ we undertook the syntheses of a series of ${ }^{\mathbf{R} 2} \mathbf{N} \mathbf{P P}_{\boldsymbol{n}}(n=2-6)$ and model compounds ${ }^{\boldsymbol{t B} u / \mathbf{R}^{2} \mathbf{N}} \mathbf{P P}_{\boldsymbol{n}}(n=2-4)$ containing $N, N$-diisopropylamino and tert-butyl groups at the opposite ends. ${ }^{5}$ The availability of this new series of poly- $p$-phenylene wires and the precise redox and optical data of their cation radicals and X-ray structures allow us to probe the extent of hole delocalization and evolution of their redox and optical

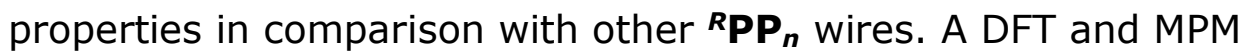
analysis of these experimental findings reveals that the energy gap between the terminal and bridging $p$-phenylene units in various ${ }^{\boldsymbol{R}} \mathbf{P P}_{\boldsymbol{n}}$ controls the evolution of redox and optical properties. The details of these findings are discussed herein.

\section{Results and Discussion}

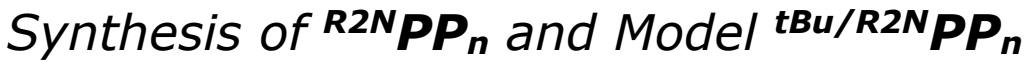

Synthesis and study of a series of $N, N$-diisopropylamino-capped ${ }^{R 2 N} \mathbf{P P}_{\boldsymbol{n}}$ wires was undertaken instead of more readily available $N, N-$ diarylamino-capped wires because of the complications from significant hole delocalization on the additional aryl groups linked to nitrogens. ${ }^{9-18}$ The diisopropylamino group was chosen as capping groups because

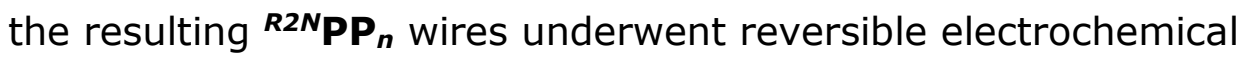
oxidation unlike dimethyl- or diethylamino-capped wires. ${ }^{19}$ An 
oxidative coupling of $N, N$-diisopropylaniline readily afforded ${ }^{\mathbf{R} N} \mathbf{P} \mathbf{P}_{\mathbf{2}}$ (see the Supporting Information for details). The synthesis of higher homologues ( $n=3-5$ ) was accomplished via efficient Suzuki coupling 20,21 between 1 -bromo-4- $N, N$-diisopropylaminobenzene and bis-boronic esters of benzene, biphenyl, and terphenyl, see Scheme 1A. The synthesis of ${ }^{\mathbf{R} 2 N} \mathbf{P P}_{\mathbf{6}}$ is depicted in Scheme $1 \mathrm{~B}$, however its solubility was decreased rather sharply ( $<1 \mathrm{mg} / 10 \mathrm{~mL}$ in $\mathrm{CH}_{2} \mathrm{Cl}_{2}$ ), in line with our previous observation with higher homologues of other

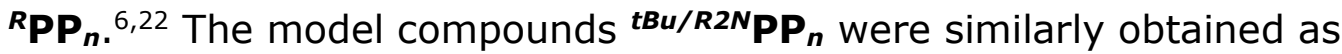
summarized in Scheme $1 C$. The structures of various ${ }^{\mathbf{R} 2 N} \mathbf{P P}_{\boldsymbol{n}}$ and

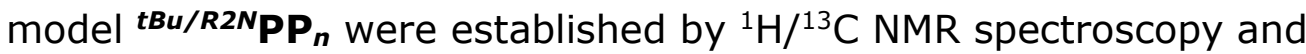
mass spectrometry and were further confirmed by X-ray crystallography of representative molecules (see Sections S6 and S7 in the Supporting Information).

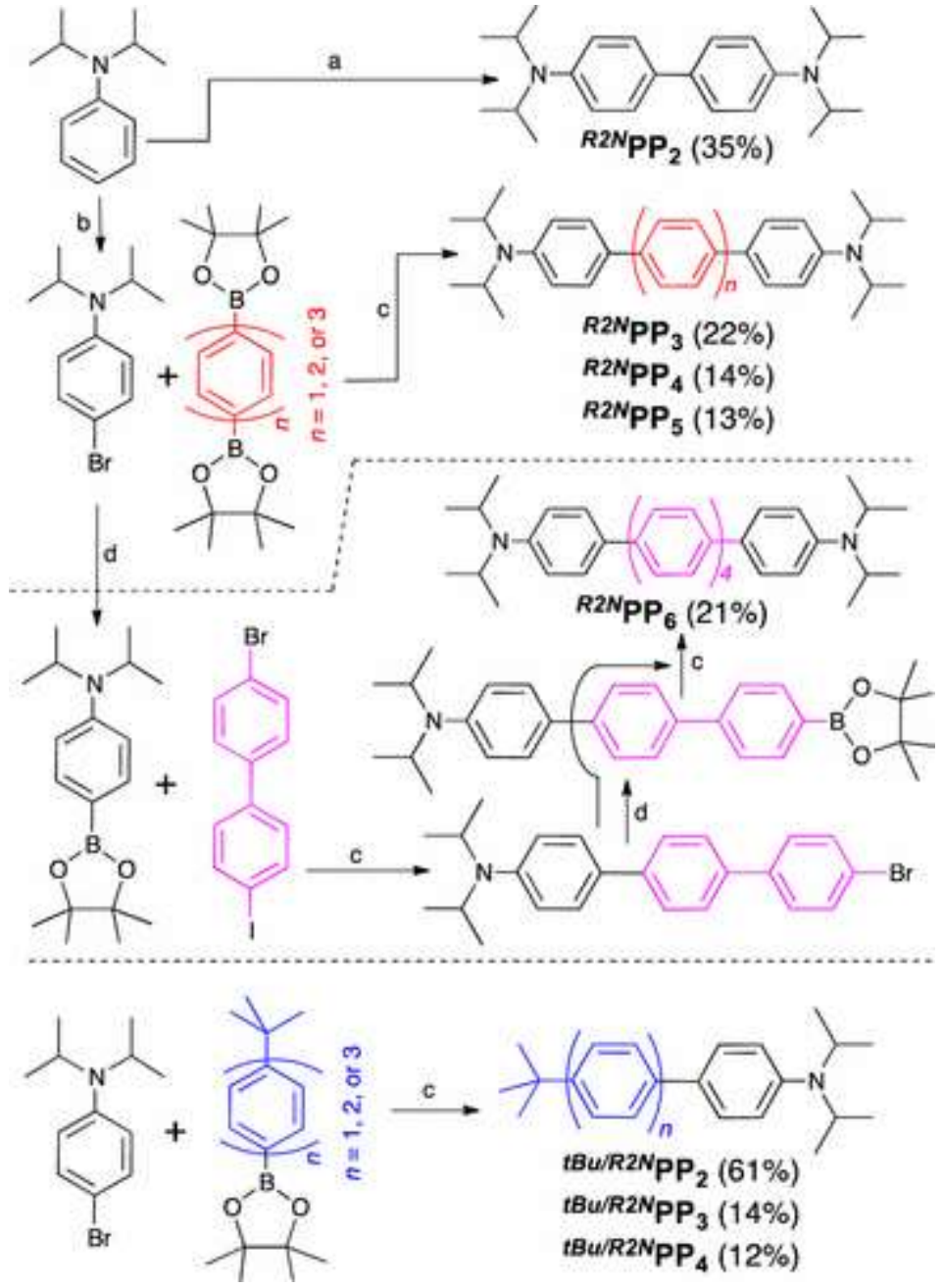

Scheme 1. Synthetic Schemes for the Preparation of ${ }^{\mathbf{R} 2} \mathbf{P} \mathbf{P}_{\boldsymbol{n}}$ and Model ${ }^{\mathbf{B} u / \mathbf{R} 2 \boldsymbol{N}} \mathbf{P} \mathbf{P}_{\boldsymbol{n}}{ }^{\mathrm{a}}$

Journal of the American Chemical Society, Vol 138, No. 50 (December 21, 2017): pg. 16337-16344. DOI. This article is (C) American Chemical Society and permission has been granted for this version to appear in e-Publications@Marquette. American Chemical Society does not grant permission for this article to be further copied/distributed or hosted elsewhere without the express permission from American Chemical Society. 
NOT THE PUBLISHED VERSION; this is the author's final, peer-reviewed manuscript. The published version may be accessed by following the link in the citation at the bottom of the page.

aConditions: (a) $\mathrm{TiCl}_{4} / \mathrm{CH}_{2} \mathrm{Cl}_{2} / 22{ }^{\circ} \mathrm{C} / 24 \mathrm{~h}$; (b) NBS/DMF/-10 ${ }^{\circ} \mathrm{C} / 40 \mathrm{~min}$; (c) $\mathrm{Pd}(\mathrm{PPh} 3) 4 / \mathrm{DME} / \mathrm{aq} \mathrm{Na2CO} / \mathrm{reflux} / 12-18 \mathrm{~h} ;$ (d)

bis(pinacolato)boron/Pd(dppf) $\mathrm{Cl}_{2} /$ dioxane/reflux/12-18 $\mathrm{h}$.

\section{Electrochemistry}

The oxidation potentials of ${ }^{\mathbf{R} 2 \mathbf{N}} \mathbf{P} \mathbf{P}_{\boldsymbol{n}}$ and model ${ }^{\mathbf{H} \boldsymbol{B} \mathbf{R} \mathbf{R} \mathbf{N}} \mathbf{P} \mathbf{P}_{\boldsymbol{n}}$ were measured by electrochemical oxidation at a platinum electrode of 2 $\mathrm{mM}$ solutions in anhydrous $\mathrm{CH}_{2} \mathrm{Cl}_{2}$ containing $0.1 \mathrm{M}$ tetra-nbutylammonium hexafluoro-phosphate $\left(n-\mathrm{Bu}_{4} \mathrm{NPF}_{6}\right)$ and were referenced to added 1,4-dimethoxy-2,5-dimethylbenzene $\left(E_{\text {ox }}=0.66 \mathrm{~V}\right.$ vs $\mathrm{Fc} / \mathrm{Fc}^{+}$) as an internal standard. ${ }^{23,24}$ The voltammograms of ${ }^{\mathbf{2} 2 \mathbf{N}} \mathbf{P} \mathbf{P}_{\boldsymbol{n}}$ and model compounds, which are all reversible, are compiled in Figure 3. Interestingly, a comparison of the $E_{\text {ox } 1}$ values of ${ }^{\mathbf{2} N} \mathbf{P P}_{\boldsymbol{n}}$, referenced to $\mathrm{Fc} / \mathrm{Fc}^{+}$, showed an increase of $\sim 350 \mathrm{mV}$ moving from $n=2\left(E_{\mathrm{ox} 1}=\right.$ $-0.08 \mathrm{~V})$ to $3\left(E_{\mathrm{ox} 1}=0.15 \mathrm{~V}\right)$ to $4\left(E_{\mathrm{ox} 1}=0.27 \mathrm{~V}\right)$, remaining constant for $n=5$ and 6 (Figure 3, Table 1). ${ }^{25}$ In contrast, the oxidation potentials of model ${ }^{\mathbf{B} u / \mathbf{R}^{2} \mathbf{N}} \mathbf{P} \mathbf{P}_{\boldsymbol{n}}$ were invariant with an increasing number of $p$-phenylenes, and their $E_{\text {ox } 1}$ values $(0.27 \pm 0.02 \mathrm{~V})$ were close to that of $\boldsymbol{R}^{\mathbf{2 N}} \mathbf{P} \mathbf{P}_{\mathbf{4}-\mathbf{6}}$, which suggests that the extent of hole

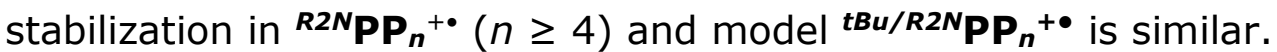

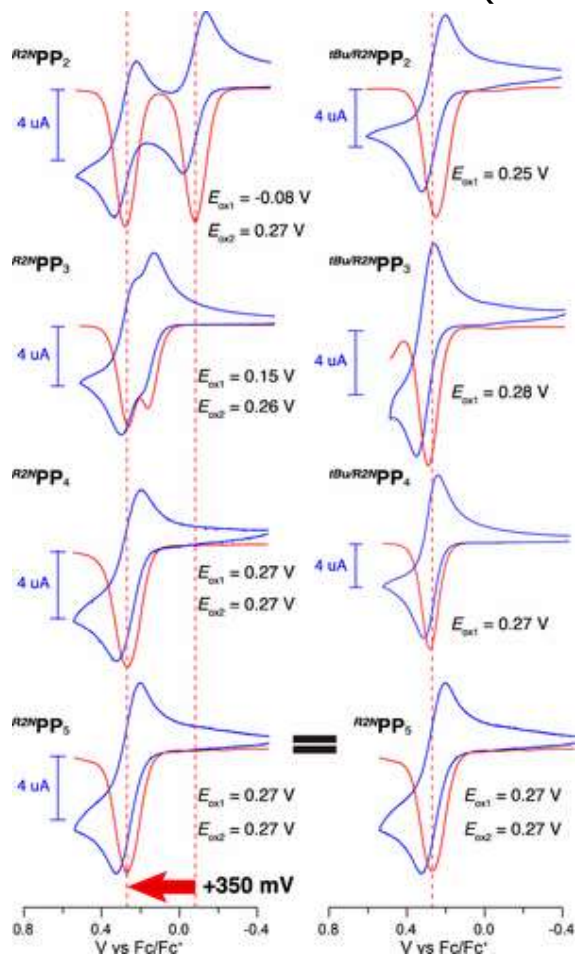

Figure 3. Cyclic (blue lines) and square-wave (red lines) voltammograms of $2 \mathrm{mM}$

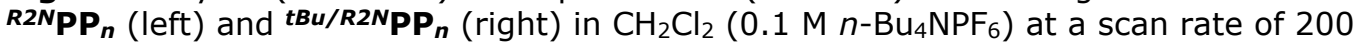


NOT THE PUBLISHED VERSION; this is the author's final, peer-reviewed manuscript. The published version may be accessed by following the link in the citation at the bottom of the page.

$\mathrm{mV} \mathrm{s}^{-1}$ and $22^{\circ} \mathrm{C}$. The scale for measure of current (in $\mu \mathrm{A}$ ) for each cyclic voltammogram is shown in blue color.

Table 1. Compilation of Experimental Oxidation Potentials $E_{\mathrm{ox} 1}\left(\mathrm{~V}\right.$ vs $\mathrm{Fc} / \mathrm{Fc}^{+}$), Absorption $\lambda_{\max }(\mathrm{nm}) / \varepsilon_{\max }\left(10^{3} \mathrm{M}^{-1} \mathrm{~cm}^{-1}\right)$ and Emission $\lambda_{\mathrm{em}}(\mathrm{nm})$ of ${ }^{\mathbf{R} 2 N} \mathbf{P} \boldsymbol{P}_{\boldsymbol{n}}$ and ${ }_{\boldsymbol{t B} \mathbf{B} \boldsymbol{R} \mathbf{R} \boldsymbol{N}} \mathbf{P P}_{\boldsymbol{n}}$, and Absorption $\lambda_{\max }(\mathrm{nm}) / \varepsilon_{\max }\left(10^{3} \mathrm{M}^{-1} \mathrm{~cm}^{-1}\right)$ of $\boldsymbol{R 2 N}^{\mathbf{N}} \mathbf{P P}_{\boldsymbol{n}}{ }^{+\bullet}$ and $t B u / R 2 N P_{n}{ }^{+\bullet}$

\begin{tabular}{|c|c|c|c|c|c|c|c|}
\hline \multirow{3}{*}{ R2NPP } & \multirow[b]{2}{*}{$n$} & \multicolumn{4}{|c|}{${ }^{R} \mathbf{P} \mathbf{P}_{n}$} & \multicolumn{2}{|c|}{${ }^{R} \mathbf{P P}_{n}{ }^{+\bullet}$} \\
\hline & & $E_{\mathrm{ox} 1}$ & $\lambda_{\max }$ & $\varepsilon_{\max }$ & $\lambda_{\text {em }}$ & $\boldsymbol{\lambda}_{\max }$ & $\varepsilon_{\max }$ \\
\hline & 2 & -0.084 & 329 & 26.6 & 393 & 1055 & 28.6 \\
\hline & 3 & 0.152 & 342 & 42.1 & 414 & 1718 & 35.3 \\
\hline & 4 & 0.268 & 348 & 37.5 & 446 & 840 & 13.5 \\
\hline & 5 & 0.268 & 349 & 45.0 & 471 & 870 & 6.8 \\
\hline & 6 & 0.268 & 347 & $-\mathrm{b}$ & 476 & 820 & $-\mathrm{b}$ \\
\hline \multirow[t]{3}{*}{$t B u / R 2 N P P_{n}$} & 2 & 0.252 & 312 & 18.5 & 373 & 713 & 18.9 \\
\hline & 3 & 0.284 & 334 & 17.0 & 421 & 826 & 17.2 \\
\hline & 4 & 0.270 & 343 & 21.0 & 456 & 880 & 14.6 \\
\hline
\end{tabular}

aThe UV-vis absorption and emission spectra of neutral compounds were recorded in $\mathrm{CH}_{2} \mathrm{Cl}_{2}$ at $22{ }^{\circ} \mathrm{C}$; see Figures $\mathrm{S} 1$ and $\mathrm{S} 2$ in the Supporting Information.

${ }^{b}$ Owing to the poor solubility of ${ }^{\mathbf{2} 2} \mathbf{P P}_{\mathbf{6}}$, its quantitative data could not be obtained (also see Figures S3, S4, and S8 in the Supporting Information).

\section{Generation and Electronic Spectroscopy of the Cation Radicals}

The relatively low oxidation potentials of ${ }^{\mathbf{R} 2 \boldsymbol{N}} \mathbf{P} \mathbf{P}_{\boldsymbol{n}}$ and the model compounds allowed for ready generation of their cation radicals in solution by quantitative redox titration using a well-characterized aromatic cation radical $\mathbf{T H E}^{+\cdot} \mathrm{SbCl}_{6}{ }^{-}$( THE $=1,2,3,4,5,6,7,8-$ octahydro-9,10-dimethoxy-1,4:5,8-dimethano-anthracene) as an oxidant $\left(E_{\text {red } 1}=0.67 \mathrm{~V}\right.$ vs Fc/Fc ${ }^{+}, \lambda_{\max }=518 \mathrm{~nm}, \varepsilon_{\max }=7300 \mathrm{~cm}^{-1} \mathrm{M}^{-}$ $\left.{ }^{1}\right) .{ }^{26}$ For example, Figure $4 \mathrm{~A}$ compiles the electronic spectra obtained by an incremental (substoichiometric) addition of a $\mathrm{CH}_{2} \mathrm{Cl}_{2}$ solution of ${ }^{\boldsymbol{t B} U / \boldsymbol{R} 2 \boldsymbol{N}} \mathbf{P P} \mathbf{P}_{\mathbf{2}}$ to a solution of $\mathbf{T H E}^{+} \mathrm{SbCl}_{6}{ }^{-}$, which showed a complete consumption of the oxidant and formation of ${ }^{\boldsymbol{t} \mathbf{B u} / \mathbf{R} \mathbf{2 N}} \mathbf{P} \mathbf{P}_{\mathbf{2}}{ }^{+\bullet}$ after the addition of 1 equiv of ${ }^{\mathbf{t B u} / \mathbf{R} 2 N} \mathbf{P} \mathbf{P}_{\mathbf{2}}$. A careful quantification at each titration point by a recently described deconvolution procedure ${ }^{12,27}$ further established a 1:1 stoichiometry of the redox reaction, i.e.,

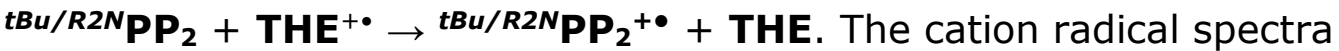
of various ${ }^{\mathbf{R} N} \mathbf{P} \mathbf{P}_{\boldsymbol{n}}$ and the model compounds shown in Figure 4B were generated similarly (Section $\mathrm{S} 5$ in the Supporting Information). Note that the absorption spectra of ${ }^{\mathbf{R} N} \mathbf{P} \mathbf{P}_{\boldsymbol{n}}{ }^{+\bullet}$ and ${ }^{\boldsymbol{t B u} / \boldsymbol{R} \mathbf{R}} \mathbf{P} \mathbf{P} \mathbf{P}_{\boldsymbol{n}}{ }^{+\bullet}$ in Figure $4 \mathrm{~B}$ 
did not change either upon a 10 -fold increase in their concentration or temperature lowering to $-50{ }^{\circ} \mathrm{C} .{ }^{28}$

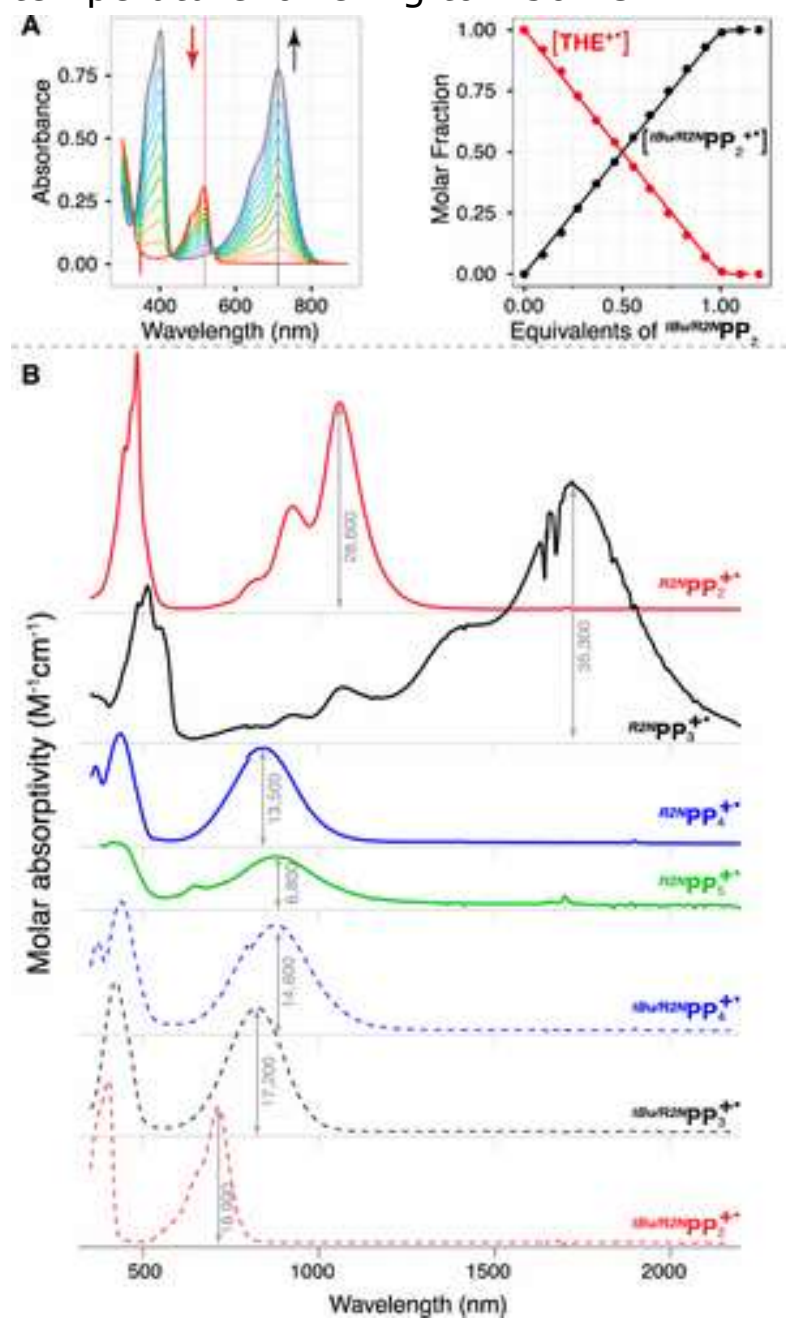

Figure 4. (A) Spectral changes and corresponding evolution of mole fractions of oxidant and electron-donor cation radicals on the representative titration of ${ }^{\mathbf{B} u / \mathbf{R} 2 \mathbf{N}} \mathbf{P} \mathbf{P}_{\mathbf{2}}$ with $42 \mu \mathrm{M} \mathrm{THE}^{+\cdot}$ in $\mathrm{CH}_{2} \mathrm{Cl}_{2}$ at $22{ }^{\circ} \mathrm{C}$. (B) Compilation of the absorption spectra of $\mathrm{CH}_{2} \mathrm{Cl}_{2}$ solutions of the cation radicals of $\boldsymbol{R}^{\mathbf{2 N}} \mathbf{P} \mathbf{P}_{\boldsymbol{n}}$ (solid lines) and ${ }^{\mathbf{B} u / \boldsymbol{R} 2 \boldsymbol{N}} \mathbf{P} \mathbf{P}_{\boldsymbol{n}}$ (dotted lines) plotted against molar absorptivity at $22^{\circ} \mathrm{C}$.

A comparison of the absorption spectra of ${ }^{\mathbf{R} 2 \mathbf{N}} \mathbf{P} \mathbf{P}_{\boldsymbol{n}}{ }^{+\bullet}$ showed that the low-energy band with prominent vibronic structure in ${ }^{\mathbf{R} 2 N} \mathbf{P P}_{\mathbf{2}}{ }^{+\bullet}$ $(1055 \mathrm{~nm})$ is red-shifted in ${ }^{\mathbf{R} 2} \mathbf{N} \mathbf{P P}_{\mathbf{3}}{ }^{+\bullet}(1718 \mathrm{~nm})$, whereas in higher homologues ${ }^{\mathbf{R} 2} \mathbf{N} \mathbf{P P}_{\mathbf{4}}{ }^{+\bullet}$ and ${ }^{\mathbf{R} 2} \mathbf{N} \mathbf{P P}_{\mathbf{5}}{ }^{+\bullet}$ it shifted back to higher energy (840 and $870 \mathrm{~nm}$, respectively). Interestingly, the absorption spectra of ${ }^{\mathbf{R} 2} \mathbf{N} \mathbf{P P}_{\mathbf{4}}{ }^{+\bullet}$ and ${ }^{\mathbf{R}} \mathbf{N} \mathbf{P} \mathbf{P}_{\mathbf{5}}{ }^{+\bullet}$ and the positions of the low-energy bands were strikingly similar to the cation radical spectrum of model ${ }^{\boldsymbol{t B} u / \mathbf{R}^{2} \mathbf{N}} \mathbf{P P}_{\mathbf{4}}{ }^{+\bullet}$, see Figure 4B and Table 1 . Consistent with the 
electrochemical analysis presented above, electronic spectroscopy of

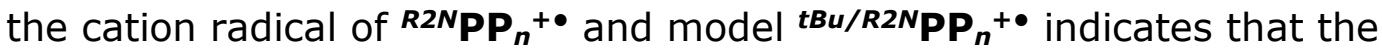
hole delocalization/stabilization in ${ }^{\mathbf{R} 2} \mathbf{P} \mathbf{P P}_{\boldsymbol{n}}{ }^{+\bullet}(n \geq 4)$ must be very similar to that in the model compounds.

\section{X-ray Crystallography}

The high stability of various ${ }^{\mathbf{R} 2 N} \mathbf{P} \mathbf{P}_{\boldsymbol{n}}{ }^{+\bullet}$ prompted us to grow single crystals for their X-ray crystallographic characterization. For example, the single crystals of ${ }^{\mathbf{R} \mathbf{N}} \mathbf{P P}_{\mathbf{2}}{ }^{+} \cdot \mathrm{SbCl}_{6}{ }^{-}$were obtained from a mixture of $\mathrm{CH}_{2} \mathrm{Cl}_{2}$ and hexanes at $-10{ }^{\circ} \mathrm{C}$, see the Supporting Information for details. Availability of the precise $\mathrm{X}$-ray structures of the neutral (Figure 5A) and cation radical (Figure 5B) of ${ }^{\mathbf{R} N} \mathbf{N} \mathbf{P P}_{\mathbf{2}}$ established that a single charge is fully delocalized over both aryl groups, as judged by the oxidation-induced bond length changes (Figure 5D). Moreover, the oxidation-induced shortening of the central C-C bond (from 1.482 to $1.433 \AA$ ) and decrease of the interplanar dihedral angle between two $p$-phenylenes (from $20.7^{\circ}$ to $0.3^{\circ}$ ) further attest to the complete delocalization of the charge (Figure 5C, D).

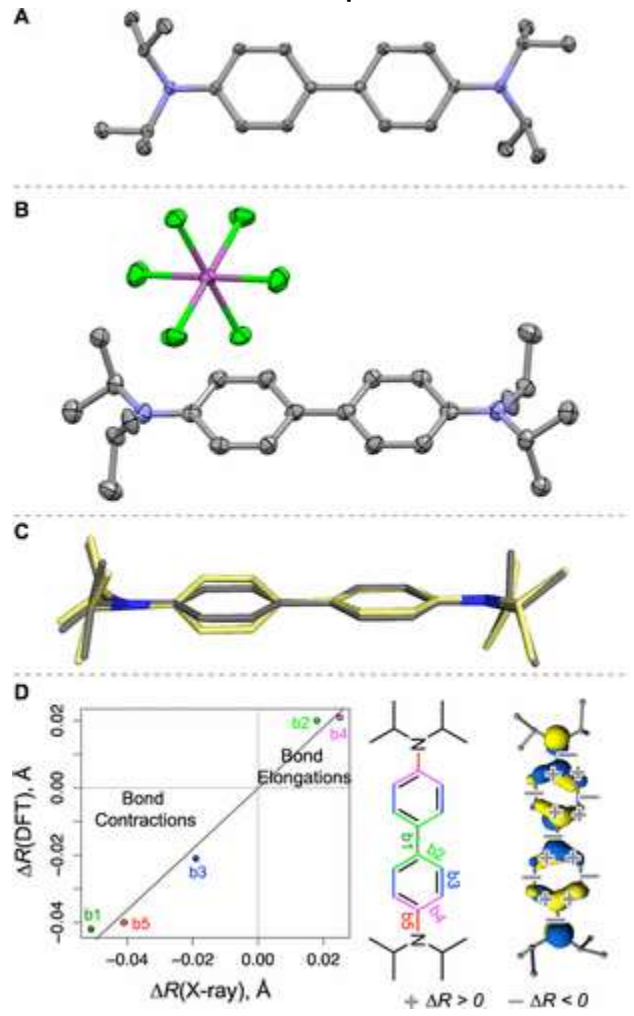

Figure 5. ORTEP diagrams ( $50 \%$ probability) of ${ }^{\mathbf{R} N} \mathbf{P P}_{\mathbf{2}}(\mathrm{A})$ and its cation radical salt (B) as well as the juxtaposition of neutral (yellow) and cation radical (gray) structures 
(C). Comparison of the oxidation-induced bond length changes obtained by X-ray crystallography and DFT calculations (D). ${ }^{29}$

It is particularly noteworthy that the elongations of the bonds in ${ }^{R 2 N} \mathbf{P} \mathbf{P}_{\mathbf{2}}{ }^{+\bullet}$ were observed at the positions of the bonding lobes of HOMO, whereas the contractions of bonds at the positions of antibonding lobes of HOMO and all bond length changes were in close agreement with those obtained by the DFT calculations (Figure 5D). Unfortunately, repeated attempts to obtain the single crystals of the higher homologues of ${ }^{\mathbf{R} \mathbf{N}} \mathbf{P P}_{\boldsymbol{n}}{ }^{+\bullet}$ were thus far unsuccessful.

\section{DFT Calculations}

DFT calculations at the B1LYP-40/6-31G(d)+PCM $\left(\mathrm{CH}_{2} \mathrm{Cl}_{2}\right)$ level of theory (see Section S8 in the Supporting Information for the computational details $)^{6,12,30-34}$ reproduced the electronic structure of ${ }^{R 2 N} \mathbf{P P}_{\boldsymbol{n}^{+\bullet}}$ as obtained by the X-ray crystallography (Figure 5). The DFT calculations showed that spin/charge (hole) was symmetrically distributed in ${ }^{\mathbf{R}} \mathbf{N} \mathbf{P} \mathbf{P}_{\mathbf{2}}{ }^{+\bullet}$, was somewhat skewed in ${ }^{\mathbf{R} 2} \mathbf{N} \mathbf{P} \mathbf{P}_{\mathbf{3}}{ }^{+\bullet}, 35$ and in higher homologues with $n \geq 4$, was shifted toward one end of the molecule and closely resembled the hole distribution in model

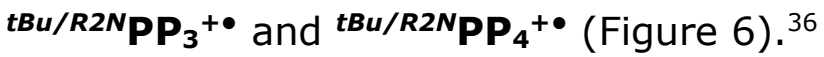
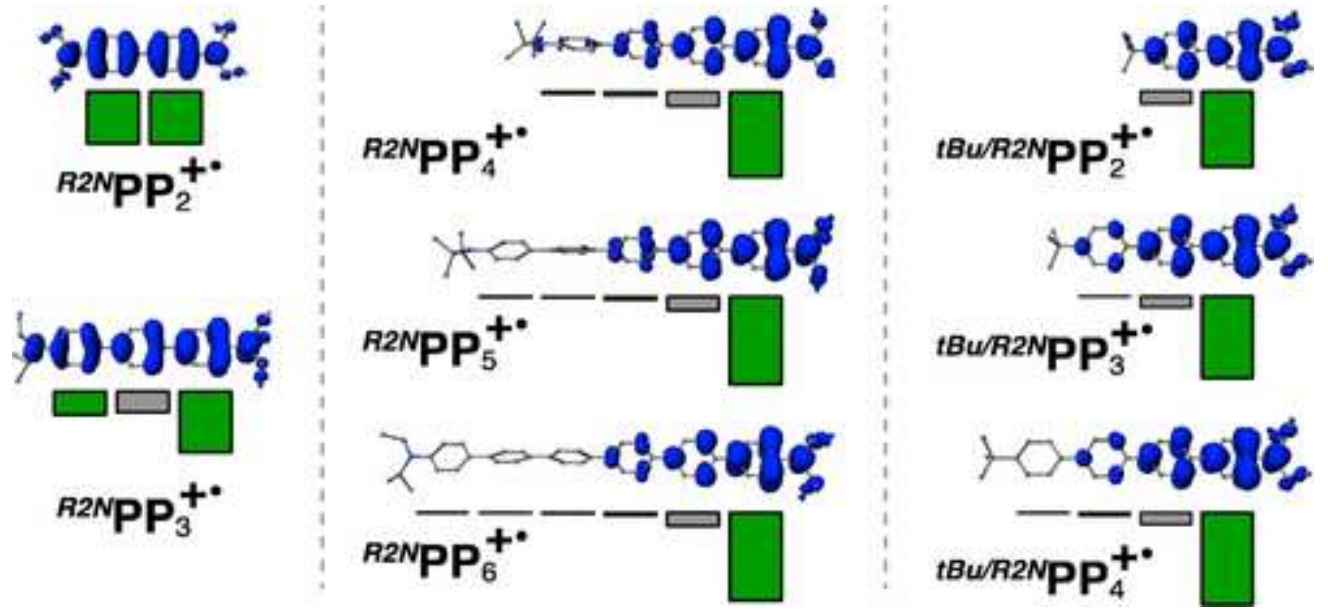

Figure 6. Spin density distribution plots $(+0.001 \mathrm{au})$ in the ground $\left(\mathrm{D}_{0}\right)$ electronic states of $\boldsymbol{R}^{\mathbf{N}} \mathbf{P P}_{\boldsymbol{n}} \boldsymbol{+}^{\boldsymbol{\bullet}}(n=2,3)$ (left), ${ }^{\mathbf{R} 2 \boldsymbol{N}} \mathbf{P P}_{\boldsymbol{n}}{ }^{+\boldsymbol{\bullet}}(n=4-6)$ (middle), and ${ }^{\boldsymbol{t B u} / \boldsymbol{R} 2 \boldsymbol{N}} \mathbf{P P}_{\boldsymbol{n}}{ }^{+\boldsymbol{\bullet}}(n$ $=2-4)$ (right) $\left[\mathrm{B} 1 \mathrm{LYP}-40 / 6-31 \mathrm{G}(\mathrm{d})+\mathrm{PCM}\left(\mathrm{CH}_{2} \mathrm{Cl}_{2}\right)\right]$. Also see Figures $\mathrm{S} 13$ and $\mathrm{S} 14$ in the Supporting Information.

The spin/charge distribution plots presented in Figure 6 clearly show that in ${ }^{\mathbf{R} \mathbf{N}} \mathbf{P} \mathbf{P}_{\boldsymbol{n}}{ }^{+\bullet}$ with $n \geq 4$ and model compounds ${ }^{\boldsymbol{t} \mathbf{B u} / \mathbf{R} \mathbf{2}} \mathbf{P P}_{\mathbf{3}}{ }^{+\bullet}$

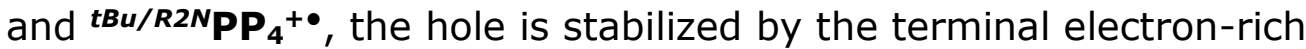


unit, in accord with the electrochemical and spectroscopic analysis (Figures 3 and 4). (TD-)DFT calculations also reproduced the experimentally observed evolution of oxidation energies of ${ }^{\mathbf{R} 2 N} \mathbf{P} \mathbf{P}_{\boldsymbol{n}}$ and

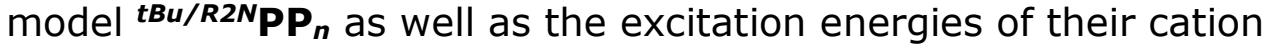
radicals (Figure 7 ). Note that the observed lowest-energy transition of ${ }^{R 2 N} \mathbf{P P}_{\boldsymbol{n}}{ }^{+\bullet}$ switches from $D_{0} \rightarrow D_{1}$ in $n=2$ and 3 to $D_{0} \rightarrow D_{2}$ in higher homologues (i.e., $n \geq 4$ ), where hole (in the ground state) shifts toward one end (see Figures S13 and S14 and Table S2 in the Supporting Information).
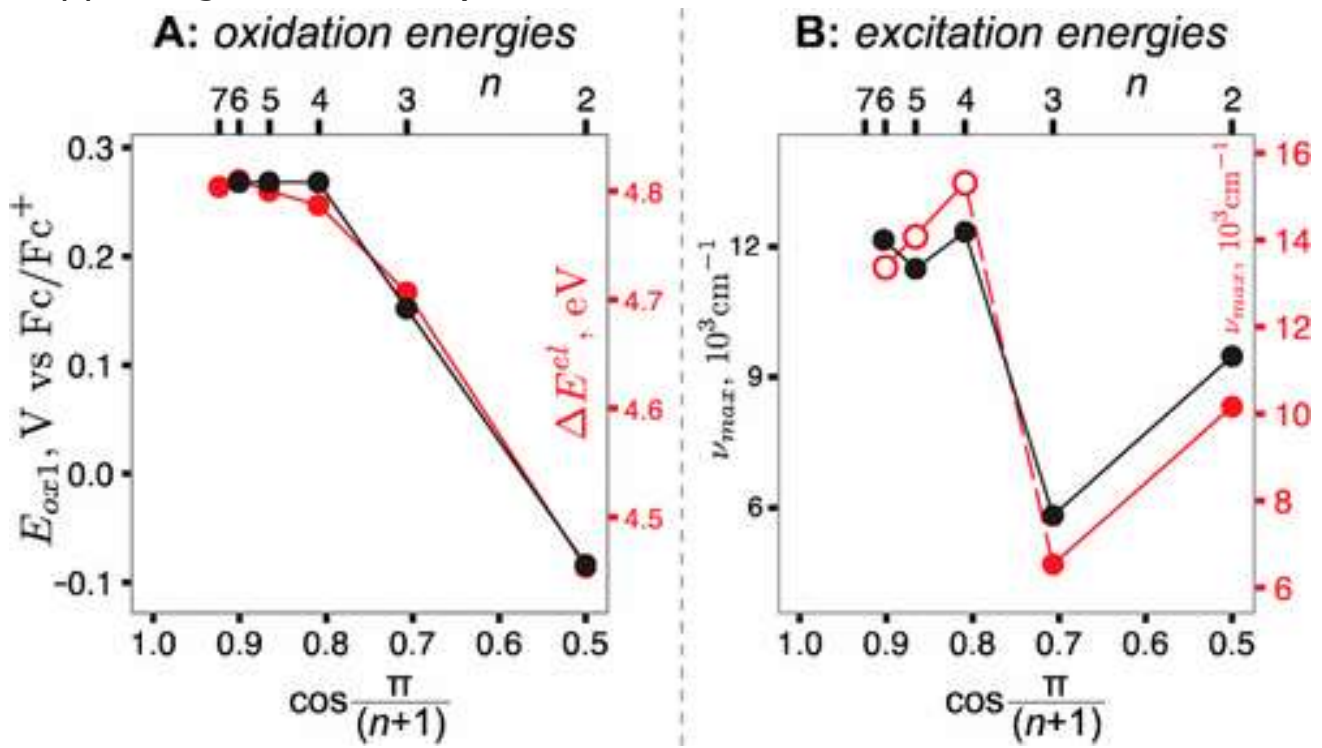

Figure 7. Comparison of the oxidation energies of ${ }^{\mathbf{R} 2 N} \mathbf{P} \mathbf{P}_{\boldsymbol{n}}(\mathrm{A})$ and excitation energies of ${ }^{R 2 N} \mathbf{P P}_{n}{ }^{+\bullet}(B) n=2$ and 3: $\mathrm{D}_{0} \rightarrow \mathrm{D}_{1}$, red solid circle, and $n=4-6: \mathrm{D}_{0} \rightarrow \mathrm{D}_{2}$, open red circles vs $\cos n /(n+1),{ }^{37}$ where $n$ is the number of $p$-phenylene units. Black solid circles (connected by black solid lines) denote experimental data points, and red circles (connected by red lines) denote data points from the (TD-)DFT calculations $\left[\mathrm{B} 1 \mathrm{LYP}-40 / 6-31 \mathrm{G}(\mathrm{d})+\mathrm{PCM}\left(\mathrm{CH}_{2} \mathrm{Cl}_{2}\right)\right]$.

\section{Application of the Two- and Three-State Marcus-Based Model to ${ }^{\boldsymbol{R}} \boldsymbol{P P}_{\mathbf{2}}$ and ${ }^{\boldsymbol{R}} \boldsymbol{P P}_{\mathbf{3}}$}

The evolution of the oxidation energies with increasing $n$ of ${ }^{R 2 N} P_{P_{n}}$ series was somewhat surprising, as the increase in oxidation potentials by 0.24 and $0.35 \mathrm{~V}$ by inserting one and two bridging $p$ phenylenes in ${ }^{\mathbf{R} 2} \mathbf{N} \mathbf{P P}_{\mathbf{2}}$ and saturation at $n=4$ were in sharp contrast with the observed decrease in the $E_{\text {ox } 1}$ values in the isoalkylsubstituted iAPP $_{\boldsymbol{n}}$ with increasing $n$, which showed saturation at $n>7$ (Figure 8). A comparison of the oxidation energies of ${ }^{\mathbf{R} 2 \boldsymbol{N}} \mathbf{P P}_{\boldsymbol{n}}$ series with our recently published ${ }^{\mathbf{R O}} \mathbf{P P}_{\boldsymbol{n}}$ series, having weaker electron- 
donating alkoxy-capping groups, showed a modest increase in $E_{\text {ox1 }}$ values $(\sim 0.10 \mathrm{~V})$ with increasing $n$, which saturated at $n=5-6$ (Figure 8).

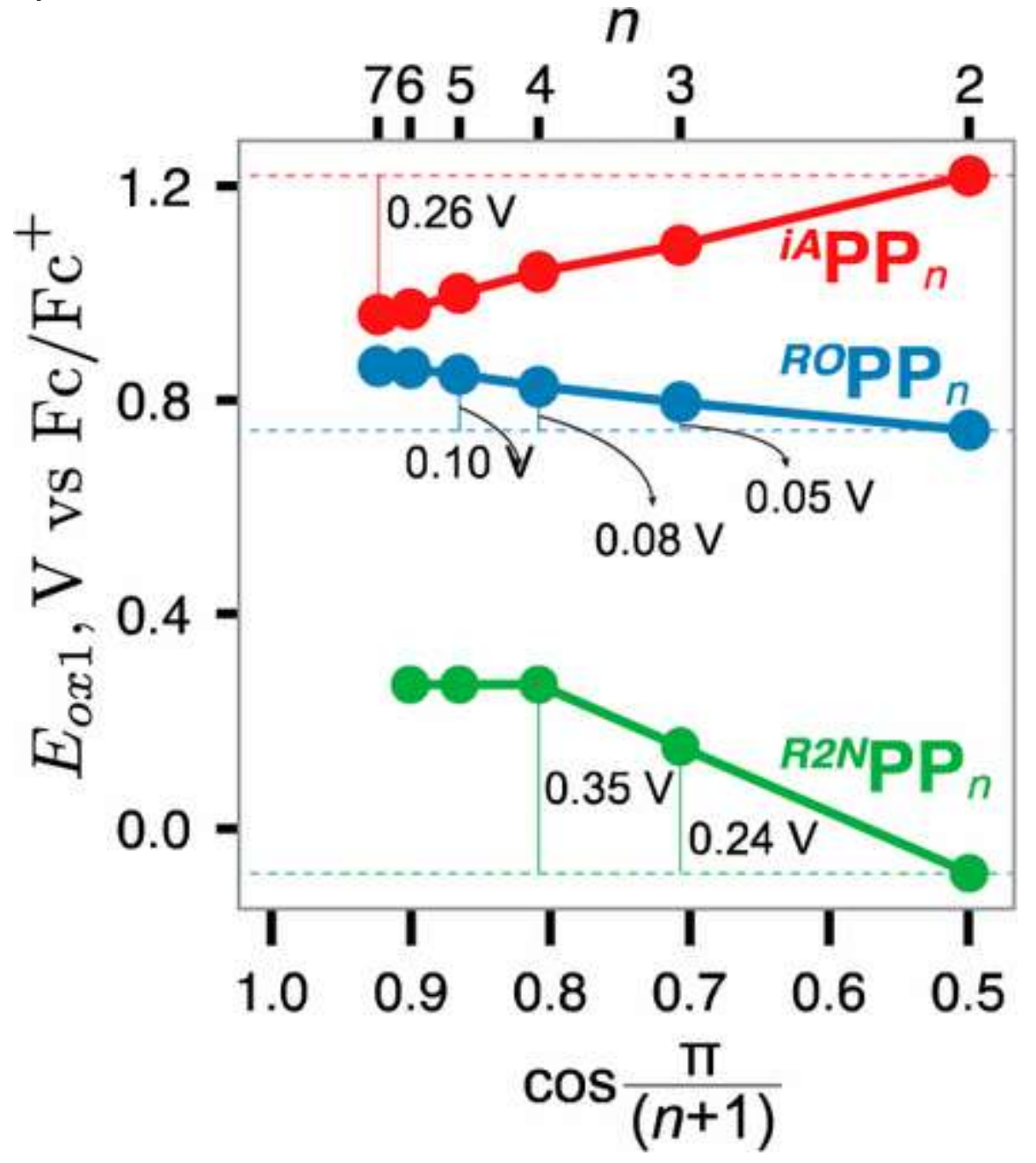

Figure 8. Showing the evolution of $E_{0 \times 1}$ of various $\boldsymbol{R}_{\mathbf{P}} \mathbf{P}_{\boldsymbol{n}}$, where $\boldsymbol{R}=\boldsymbol{i A}, \boldsymbol{R O}$, and $\boldsymbol{R} \mathbf{2 N}$, vs $\cos n /(n+1),{ }^{37}$ where $n$ is the number of $p$-phenylene units.

In order to account for this unusual evolution of the redox potentials of poly- $p$-phenylenes $\left({ }^{\boldsymbol{R}} \mathbf{P} \mathbf{P}_{\boldsymbol{n}}\right)$ with end-capping substituents (i.e., $\boldsymbol{R}=\boldsymbol{i \boldsymbol { A }}, \boldsymbol{R O}$, or $\boldsymbol{R} \mathbf{2 N}$ ) of increasing electron-donor strength, we analyzed the ${ }^{\boldsymbol{R}} \mathbf{P} \mathbf{P}_{\mathbf{2}}{ }^{+\bullet}$ and ${ }^{\boldsymbol{R}} \mathbf{P} \mathbf{P}_{\mathbf{3}}{ }^{+\bullet}$ series using our recently developed Marcus-based MPM, ${ }^{6,34}$ as follows: Based on the two-state Marcus model, the model Hamiltonian $\mathbf{H} \mathbf{2}$ for ${ }^{\boldsymbol{R}} \mathbf{P} \mathbf{P}_{\mathbf{2}}{ }^{+\bullet}$ (Figure 9) can be simplified, as in eq 1 , by noting that the hole is symmetrically distributed in ${ }^{\boldsymbol{R}} \mathbf{P} \mathbf{P}_{\mathbf{2}}{ }^{+\bullet}$, i.e., the position of the hole corresponding to the minimum of the adiabatic ground-state energy $x_{\min }\left({ }^{R} \mathbf{P} \mathbf{P}_{\mathbf{2}}{ }^{+\bullet}\right)=1 / 2 . A$ similar assumption of symmetrical (but not necessarily even) hole

Journal of the American Chemical Society, Vol 138, No. 50 (December 21, 2017): pg. 16337-16344. DOI. This article is (C) American Chemical Society and permission has been granted for this version to appear in e-Publications@Marquette. American Chemical Society does not grant permission for this article to be further copied/distributed or hosted elsewhere without the express permission from American Chemical Society. 
distribution in ${ }^{\boldsymbol{R}} \mathbf{P} \mathbf{P}_{\mathbf{3}}{ }^{+\bullet}$ [i.e., $\boldsymbol{X}_{\min }\left(\boldsymbol{R} \mathbf{P} \mathbf{P}_{\mathbf{3}}{ }^{+\bullet}\right)=1$ ] also simplifies the Hamiltonian $\mathbf{H 3}$ (i.e., eq 2) for the three-state parabolic model applicable to ${ }^{\boldsymbol{R}} \mathbf{P P}_{\mathbf{3}}{ }^{+\bullet}$ (Figure 9 ).

$$
\begin{aligned}
\mathbf{H} 2 & =\left(\begin{array}{ll}
\lambda / 4-\Delta \varepsilon & H_{a b} \\
H_{a b} & \lambda / 4-\Delta \varepsilon
\end{array}\right)(1) \\
\mathbf{H} 3 & =\left(\begin{array}{lll}
\lambda-\Delta \varepsilon & H_{a b} & 0 \\
H_{a b} & 0 & H_{a b} \\
0 & H_{a b} & \lambda-\Delta \varepsilon
\end{array}\right)(2)
\end{aligned}
$$

Marcus (Two-State) Model

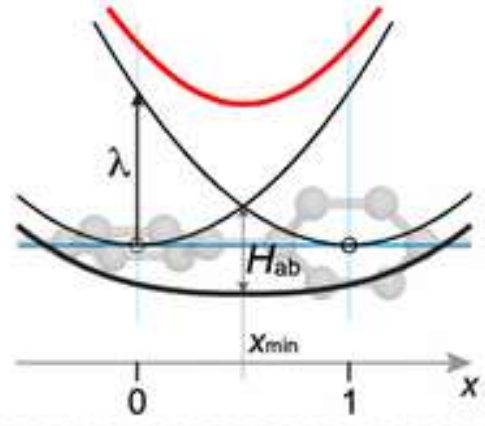

Two-state Hamiltonian H2
Three-State Model

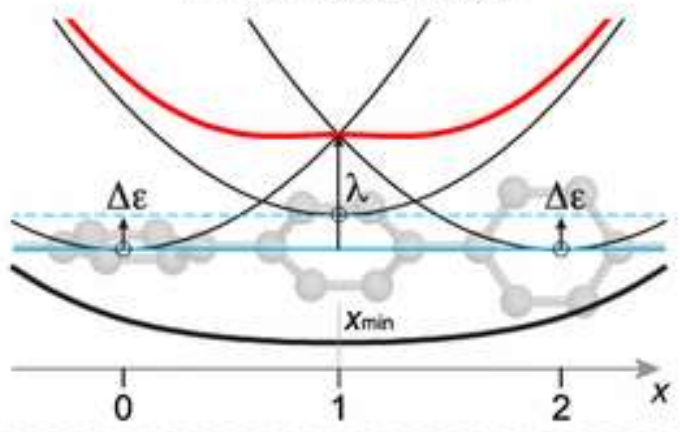

Three-state Hamiltonian $\mathbf{H 3}$

$$
\left(\begin{array}{cc}
\lambda x^{2}-\Delta \varepsilon & H_{a b} \\
H_{a b} & \lambda(1-x)^{2}-\Delta \varepsilon
\end{array}\right) \quad\left(\begin{array}{ccc}
\lambda x^{2}-\Delta \varepsilon & H_{a b} & 0 \\
H_{a b} & \lambda(1-x)^{2} & H_{a b} \\
0 & H_{a b} & \lambda(2-x)^{2}-\Delta \varepsilon
\end{array}\right)
$$

Figure 9. Graphical representation of the two- and three-state parabolic models and the corresponding model Hamiltonians $\mathbf{H 2}$ and $\mathbf{H 3}$, where $H_{\mathrm{ab}}$ is the electronic coupling between the interacting units, $\lambda$ is the reorganization energy, $\Delta \varepsilon$ is the energy difference between the capped terminal unit and bridging $p$-phenylene unit, and $x$ is the structural/solvent reorganization coordinate.

The Hamiltonian matrices in eqs 1 and 2 for different endcapping groups, represented in Figure 10, can be analytically diagonalized, and the resulting eigenvalues (eqs S1 and S2 in the Supporting Information) provide adiabatic ground-state energies, which relate directly to $E_{\mathrm{ox} 1}$ of ${ }^{\boldsymbol{R}} \mathbf{P P}_{\mathbf{2}}$ and ${ }^{\boldsymbol{R}} \mathbf{P P}_{\mathbf{3}}$. For example, a comparison of the lowest eigenvalues of $\mathbf{H 2}$ and $\mathbf{H 3}$ with different values of $\Delta \varepsilon$ and constant $H_{\mathrm{ab}}$ and $\lambda$ (see Section S9 in the Supporting Information for details) shows that $E_{\text {ox } 1}$ of ${ }^{\boldsymbol{R}} \mathbf{P P}_{\mathbf{3}}$ would be similar to $E_{\text {ox } 1}$ of ${ }^{\boldsymbol{R}} \mathbf{P P}_{\mathbf{2}}$ [i.e., $\Delta E_{\text {ox }}=E_{\text {ox } 1}\left({ }^{\boldsymbol{R}} \mathbf{P P}_{\mathbf{3}}\right)-E_{\text {ox } 1}\left({ }^{\boldsymbol{R}} \mathbf{P P}_{\mathbf{2}}\right)=0$ ] if the energy difference between the capped terminal and bridging $p$-phenylene unit $(\Delta \varepsilon)$ was comparable to the coupling $\left(H_{\mathrm{ab}}\right)$, i.e., $\Delta \varepsilon \approx H_{\text {ab }}$ (i.e., $\boldsymbol{R}=$ 
$\boldsymbol{R O}$ ). In contrast, the oxidation potential is predicted to decrease (i.e., $\Delta E_{\text {ox }}<0$ ) when $\Delta \varepsilon<H_{\text {ab }}$ (i.e., $\boldsymbol{R}=\boldsymbol{i A}$ ) and increase (i.e., $\Delta E_{\text {ox }}>0$ ) when $\Delta \varepsilon>H_{\text {ab }}$ (i.e., $\boldsymbol{R}=\boldsymbol{R} \mathbf{2} \boldsymbol{N}$ ), Figure $10 .{ }^{38}$

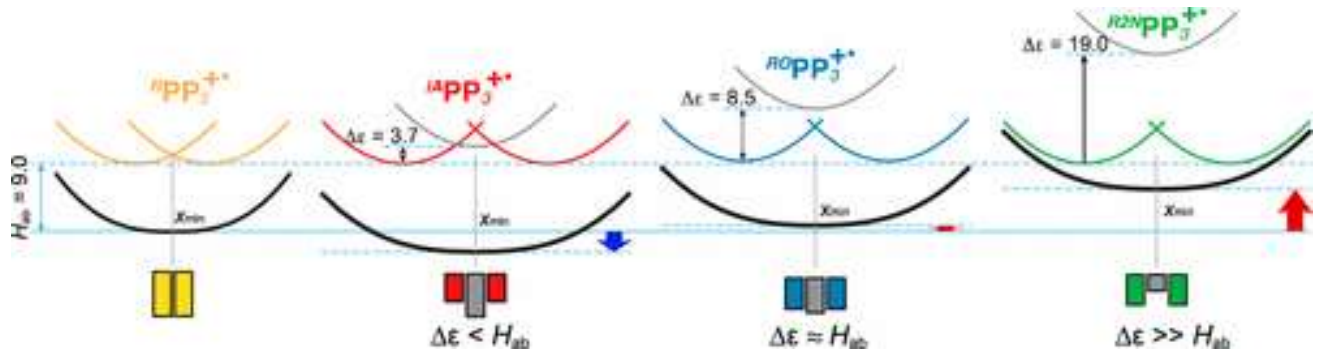

Figure 10. Comparison of the hole stabilization and distribution in ${ }^{\mathbf{R}} \mathbf{P} \mathbf{P}_{\mathbf{2}}{ }^{+\bullet}$ and $\boldsymbol{R}_{\mathbf{P P}} \mathbf{P}_{\mathbf{3}}{ }^{\mathbf{\bullet}}$ calculated using two- and three-state parabolic models defined in Figure 9. Thick blue/red arrows show increase/decrease in hole stabilization in ${ }^{\boldsymbol{R}} \mathbf{P P}_{\mathbf{3}}{ }^{+\bullet}$ with respect to $\boldsymbol{R} \mathbf{P P}_{\mathbf{2}}{ }^{+\bullet}$. Parameters used in the multiparabolic model: $H_{\mathrm{ab}}=9.0, \lambda=1.0, \Delta \varepsilon(\boldsymbol{H})=0$, $\Delta \varepsilon(\boldsymbol{i A})=3.7, \Delta \varepsilon(\boldsymbol{R O})=8.5$. The value of the $\Delta \varepsilon(\boldsymbol{R} \mathbf{2 N})=19.0$ was obtained based on the linear correlation between the values of $\Delta \varepsilon$ vs the ionization potentials of model compounds, i.e., benzene $(9.24 \mathrm{eV})$, toluene $(8.83 \mathrm{eV})$, anisole $(8.25 \mathrm{eV})$, and dimethylaminobenzene $(7.15 \mathrm{eV})$, see Section S9 and Figure S19 in the Supporting Information.

Comparison of the hole stabilization as elucidated with the MPM for various ${ }^{\boldsymbol{R}} \mathbf{P} \mathbf{P}_{\boldsymbol{n}}$ is depicted graphically in Figure 10 . Here we see that a smaller $\Delta \varepsilon$ in case of isoalkyl-capped poly-p-phenylenes leads to effective stabilization of hole and thereby lowering of the oxidation potentials in ${ }^{i} \mathbf{P P}_{\mathbf{3}}{ }^{+\bullet}$ in comparison with ${ }^{i \mathbf{A}} \mathbf{P P}_{\mathbf{2}}{ }^{+\bullet}$. In contrast, the larger $\Delta \varepsilon$ values for ${ }^{\mathbf{R O}} \mathbf{P} \mathbf{P}_{\boldsymbol{n}}$ and ${ }^{\mathbf{R} 2 \mathbf{N}} \mathbf{P} \mathbf{P}_{\boldsymbol{n}}$, which arise from the large energy difference between the terminal and bridging $p$-phenylene units, impede interchromophoric interaction between the terminal units and thereby leading to destabilization of the hole (Figure 10). Note that modest destabilization of $\boldsymbol{R O}_{\mathbf{P}} \mathbf{P}_{\mathbf{3}}{ }^{\mathbf{*}}\left(\Delta E_{\mathrm{ox}}=0.05 \mathrm{~V}\right)$ as compared to ${ }^{R 2 N} \mathbf{P P}_{3}{ }^{+\bullet}\left(\Delta E_{0 x}=0.24 \mathrm{~V}\right)$ is directly related to the increased $\Delta \varepsilon$ value (Figure 10). ${ }^{39}$

The MPM analysis further demonstrates that the amount of hole on the central $p$-phenylene in ${ }^{\mathbf{R}} \mathbf{P P}_{\mathbf{3}}{ }^{+\bullet}$, obtained directly from analytical expression for eigenvectors (eq S4 in the Supporting Information) of model Hamiltonian matrix in eq 2 , depletes upon increasing the $\Delta \varepsilon$ between the end-capped terminal and bridging units (Figure 10). In the case of ${ }^{\mathbf{2} N} \mathbf{P P}_{\mathbf{3}}{ }^{+\boldsymbol{\bullet}}$, where $\Delta \varepsilon$ is largest, the hole tends to concentrate onto the electron-rich terminal units, which leads to destabilization of the hole as verified by increased oxidation potentials by $\sim 0.24 \mathrm{~V}$. In contrast, for ${ }^{\boldsymbol{R}} \mathbf{P P}_{\mathbf{3}}{ }^{+\bullet}$ the hole is concentrated more or less equally on terminal and bridging units, owing to the relatively 
modest increase in $\Delta \varepsilon$. Finally, the hole distribution in ${ }^{\mathbf{R} O} \mathbf{P} \mathbf{P}_{\mathbf{3}}{ }^{+\bullet}$ represents a case of $\Delta \varepsilon \approx H_{\mathrm{ab}}$, as attested by a minimal destabilization of the hole by $\sim 0.05 \mathrm{~V}$, as compared to ${ }^{\boldsymbol{R} O} \mathbf{P} \mathbf{P}_{\mathbf{2}}{ }^{+\bullet} .40$

\section{Application of Multistate Model to ${ }^{\mathbf{R} 2 \boldsymbol{N}} \boldsymbol{P P}_{\boldsymbol{n}}{ }^{+\bullet}$}

The two- and three-state parabolic models presented in Figure 9 and 10 clearly account for the observed trend in the evolution of the oxidation energies. We have recently shown that more precise description of the hole distribution in the ground and especially in the excited states of poly- $p$-phenylene wires and the resulting redox and optical properties are better described using the a bell-shaped function rather than a parabola. ${ }^{41}$ Accordingly, herein we employ the multistate model (MSM) with bell-shaped function to ${ }^{\boldsymbol{R}^{2} \mathbf{N}} \mathbf{P P}_{\boldsymbol{n}}{ }^{+\bullet}$ as follows (also see Section S10 in the Supporting Information).

The eigenvectors obtained from diagonalization of the $n$-state Hamiltonian matrices in MSM provided hole distributions with uncanny similarity with the spin/charge distribution obtained by the DFT calculations, i.e., the hole shifts toward one end of the ${ }^{\boldsymbol{R} \mathbf{N}} \mathbf{P} \mathbf{P}_{\boldsymbol{n}}{ }^{+\boldsymbol{\bullet}}$ chain for $n \geq 4$ (Figure S26 in the Supporting Information). Moreover, the eigenvalues provided oxidation energies of ${ }^{\mathbf{R} N} \mathbf{P P}_{\boldsymbol{n}}$, which increase with increasing number of $p$-phenylene units and saturate for $n \geq 4$ (compare Figures 11A and 7). Interestingly, a simulated plot (Figure 11 , gray) of oxidation energies of hypothetical ${ }^{\mathbf{R}} \mathbf{P P}_{\boldsymbol{n}}$ wires with a wide range of energy gaps between the end-capped terminal and bridging internal units $(\Delta \varepsilon=0-70)$ further demonstrate three different regimes in the evolution of the oxidation energies, among which ${ }^{\boldsymbol{R}} \mathbf{P} \mathbf{P}_{\boldsymbol{n}}$ wires with $\boldsymbol{R}=\boldsymbol{i A}, \boldsymbol{R O}, \boldsymbol{R} \mathbf{2 N}$ represent limiting cases, i.e., $\Delta \varepsilon<H_{\mathrm{ab}}$ (i.e., $\boldsymbol{R}=$ iA), $\Delta \varepsilon \approx H_{\mathrm{ab}}$ (i.e., $\boldsymbol{R}=\boldsymbol{R} \boldsymbol{O}$ ), and $\Delta \varepsilon>H_{\mathrm{ab}}$ (i.e., $\boldsymbol{R}=\boldsymbol{R} \mathbf{2} \mathbf{N}$ ). It is important to note that the nature of the observed lowest-energy transition changes from $\mathrm{D}_{0} \rightarrow \mathrm{D}_{1}$ in fully delocalized ${ }^{\mathbf{R} 2 \boldsymbol{N}} \mathbf{P P}_{\boldsymbol{n}}{ }^{+\bullet}(n=2$, $3)$ to $D_{0} \rightarrow D_{2}$ in longer homologues $(n \geq 4)$ and was accurately predicted by MSM (compare Figures $11 \mathrm{~B}$ and 7 ). 

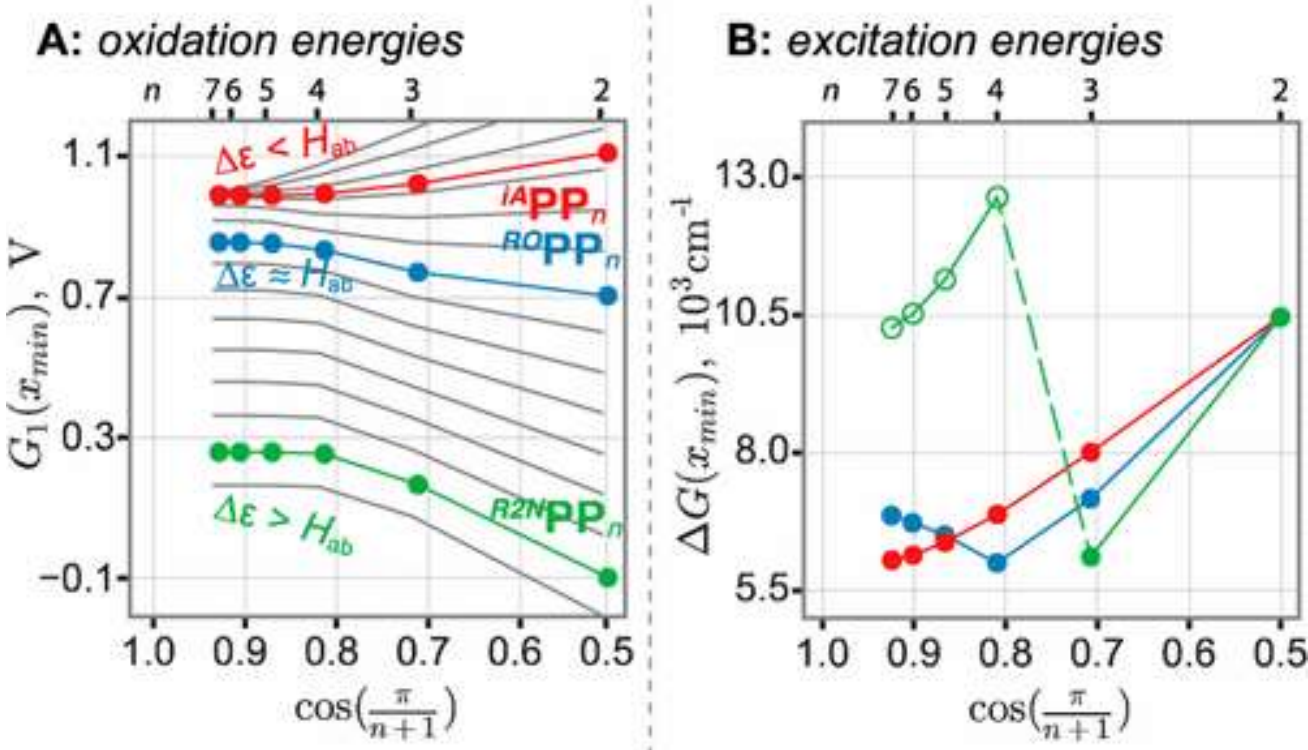

Figure 11. (A) Oxidation energies $G_{1}\left(x_{\min }\right)$ of $\boldsymbol{R}_{\mathbf{P P}}(n=2-7, \boldsymbol{R}=\boldsymbol{i A}, \boldsymbol{R O}$, or $\boldsymbol{R} \mathbf{2 N})$, obtained from MSM, against cos $n /(n+1)$ trend. ${ }^{37}$ A simulated plot of the oxidation energies $G_{1}\left(X_{\min }\right)$ obtained using MSM for a range of energy gaps between the endcapped terminal and bridging internal units $(\Delta \varepsilon=0-70)$ in hypothetical ${ }^{R} \mathbf{P P}_{\boldsymbol{n}}$ wires is

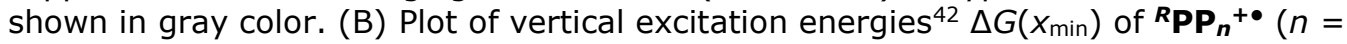
$2-7, \boldsymbol{R}=\boldsymbol{i A}, \boldsymbol{R O}$, or $\boldsymbol{R 2} \mathbf{N})$, obtained from MSM, against cos $n /(n+1)$ trend. ${ }^{37}$ Solid circles correspond to the $D_{0} \rightarrow D_{1}$ transition (i.e., $\left.\Delta G\left(x_{\min }\right)=G_{2}\left(x_{\min }\right)-G_{1}\left(x_{\min }\right)\right)$, and open circles correspond to the $D_{0} \rightarrow D_{2}$ transition (i.e., $\Delta G\left(x_{\min }\right)=G_{3}\left(x_{\min }\right)-G_{1}\left(x_{\min }\right)$ ). The oxidation and excitation energies obtained from MSM were scaled to experimental data.

Thus, MSM successfully reproduced the evolution of oxidation energies and vertical excitation energies as well as the nature of the lowest-energy transitions across all ${ }^{\boldsymbol{P}} \mathbf{P P}_{\boldsymbol{n}}{ }^{+\bullet}$ series with $\boldsymbol{R}=\boldsymbol{i A}, \boldsymbol{R O}$, and $\boldsymbol{R} \mathbf{2 N}$ (Figure 11), obtained by experiment or DFT calculations, and provided a clear rationale of the differing trend in the evolution of redox and optical properties with increasing $\Delta \varepsilon$ between the endcapped terminal and bridging internal units.

\section{Conclusions}

In this study, we undertook a detailed examination of the strikingly different trends of evolution of experimental $E_{\mathrm{ox} 1}$ and effective conjugation length (ECL) of end-capped poly-p-phenylenes $\left({ }^{R} \mathbf{P P}_{\boldsymbol{n}}\right)$ with electron-rich substituents. For example, we have earlier shown that alkyl-capped poly- $p$-phenylenes ( ${ }^{i A} \mathbf{P P}_{\boldsymbol{n}}$ ) show a decrease $(-0.26 \mathrm{~V})$ in $E_{0 \times 1}$ with increasing number of $p$-phenylenes $(\mathrm{ECL}=7)$, 
while alkoxy-capped poly- $p$-phenylenes $\left({ }^{\boldsymbol{R O}} \mathbf{P} \mathbf{P}_{\boldsymbol{n}}\right)$ show an increase $(+0.10 \mathrm{~V})$ in $E_{\mathrm{ox} 1}$ with increasing number of $p$-phenylenes $(E C L=5){ }^{6}$

In order to reconcile this divergent behavior, we synthesized a series of ${ }^{\mathbf{R} N} \mathbf{P P}_{\boldsymbol{n}}(n=2-6)$ with highly electron-rich $N, N$ diisopropylamino end-capping groups and the model compounds

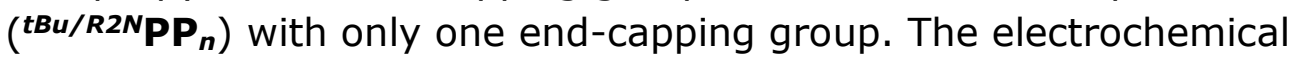
analysis of ${ }^{\mathbf{R} N} \mathbf{P} \mathbf{P}_{\boldsymbol{n}}$ and model compounds showed a dramatic increase $(+0.35 \mathrm{~V})$ in $E_{\text {ox } 1}$ with increasing $n\left[{ }^{\mathbf{R} N} \mathbf{P} \mathbf{P}_{2}:-0.08 \mathrm{~V},{ }^{\mathbf{R} N} \mathbf{P} \mathbf{P}_{3}: 0.15 \mathrm{~V}\right.$,

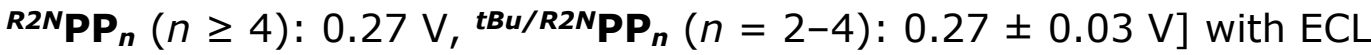
$=3$. The optical spectra of ${ }^{\mathbf{R} 2} \mathbf{N} \mathbf{P} \mathbf{P}_{\boldsymbol{n}}{ }^{+\bullet}$, obtained via quantitative redox titrations with a robust one-electron aromatic oxidant, showed a red shift in low-energy absorption band going from ${ }^{\mathbf{R} 2} \mathbf{P P}_{\mathbf{2}}{ }^{+\bullet}(1055 \mathrm{~nm})$ to ${ }^{R 2 N} \mathbf{P P}_{3}{ }^{+\bullet}(1718 \mathrm{~nm})$, while the spectra of higher homologues of ${ }^{R 2 N} \mathbf{P P}_{\boldsymbol{n}^{+}}{ }^{+}(n \geq 4)$ were remarkably similar to the absorption spectrum of model ${ }^{\boldsymbol{H} u / \mathbf{R}^{2} \mathbf{N}} \mathbf{P} \mathbf{P}_{4}{ }^{+\bullet}$ with a considerably blue-shifted absorption band at $\sim 880 \mathrm{~nm}$. The ECL $=3$ for ${ }^{\mathbf{R} 2 \mathbf{N}} \mathbf{P P}_{\boldsymbol{n}}{ }^{+\bullet}$, determined by electrochemical analysis, is further corroborated by electronic spectroscopy which shows that the hole must be delocalized in ${ }^{\mathbf{R} 2} \mathbf{N} \mathbf{P P}_{2}{ }^{+\bullet}$ and ${ }^{\mathbf{R} 2} \mathbf{N} \mathbf{P P}_{3}{ }^{+\bullet}$ (redshifted absorption band), while it lies toward one end of the molecule in higher homologues ${ }^{\mathbf{R} \mathbf{N}} \mathbf{P P}_{\boldsymbol{n}}{ }^{+\bullet}, n \geq 4$.

The analysis presented above was further supported by the DFT calculations [B1LYP-40/6-31G(d)+PCM $\left(\mathrm{CH}_{2} \mathrm{Cl}_{2}\right)$ ], which reproduced the experimental redox and optical properties of ${ }^{\mathbf{R} N \mathbf{N}} \mathbf{P} \mathbf{P}_{\boldsymbol{n}} /{ }^{\mathbf{R} \mathbf{N}} \mathbf{P} \mathbf{P}_{\boldsymbol{n}}{ }^{+\boldsymbol{\bullet}}$ and showed that spin/charge distribution indeed shifts toward one end of the molecule in higher homologues $\left({ }^{\boldsymbol{R} 2 N} \mathbf{P} \mathbf{P}_{\boldsymbol{n}}{ }^{+\bullet}, n \geq 4\right)$, similar to the model ${ }^{\boldsymbol{t} \boldsymbol{B} u / \boldsymbol{R}^{2} \mathbf{N}} \mathbf{P} \mathbf{P}_{4}{ }^{+\boldsymbol{\bullet}}$. Moreover, the hole is fully delocalized in ${ }^{\boldsymbol{R} \mathbf{N}} \mathbf{P} \mathbf{P}_{3}{ }^{+\bullet}$ and ${ }^{R 2 N} \mathbf{P P}_{2}{ }^{+\bullet}$, and the oxidation-induced bond length changes in ${ }^{R 2 N} \mathbf{P} \mathbf{P}_{2}{ }^{+\bullet}$, obtained by DFT calculations, were in complete agreement with those obtained by precise $X$-ray structures of ${ }^{\mathbf{R} 2 N} \mathbf{P} \mathbf{P}_{2}$ and ${ }^{R 2 N} \mathbf{P P}_{3}{ }^{+\bullet}$.

In order to ascertain the role of the energy gap $(\Delta \varepsilon)$ between the end-capped terminal and bridging $p$-phenylene units on the effective conjugation length, we applied our recently developed Marcus-based MSM. Hamiltonian matrices of two- and three-state parabolic models applicable to ${ }^{\boldsymbol{R}} \mathbf{P} \mathbf{P}_{2}{ }^{+\bullet}$ and ${ }^{\boldsymbol{R}} \mathbf{P P}_{3}{ }^{+\bullet}$ were simplified by assumption of symmetrical hole distribution and analytically 
diagonalized to produce eigenvalues (directly related to oxidation energies) and eigenvectors (related to the distribution of the hole). A comparison of the simplified Hamiltonian matrices for ${ }^{\boldsymbol{R}} \mathbf{P} \mathbf{P}_{2}{ }^{+\bullet}$ and ${ }^{R} \mathbf{P P}_{3}{ }^{+\bullet}$ provided a direct relationship between $\Delta \varepsilon$ and electronic coupling between adjacent $p$-phenylenes $H_{\mathrm{ab}}$ and showed that oxidation energies will decrease with increasing number of $p$ phenylenes if $\Delta \varepsilon<H_{a b}$ (i.e., ${ }^{\text {iAPP }}$ ), increase when $\Delta \varepsilon>H_{a b}$ (i.e., $\boldsymbol{R 2 N}_{\mathbf{P}} \mathbf{P}_{\boldsymbol{n}}$ ), and show only a minimal change when $\Delta \varepsilon \approx H_{\mathrm{ab}}$ (i.e., ${ }^{\boldsymbol{R} O} \mathbf{P} \mathbf{P}_{\boldsymbol{n}}$ ). Moreover, a more pronounced increase in the oxidation energies going from $n=2$ to 3 of ${ }^{\mathbf{R} 2 \mathbf{N}} \mathbf{P P}_{\boldsymbol{n}}(0.24 \mathrm{~V})$ as compared to ${ }^{\boldsymbol{R} O} \mathbf{P P}_{\boldsymbol{n}}(0.05 \mathrm{~V})$ was consistent with an increase in $\Delta \varepsilon$ from ${ }^{\boldsymbol{R} O} \mathbf{P P}_{\boldsymbol{n}}(8.5)$ to ${ }^{\boldsymbol{R} 2 \boldsymbol{N}} \mathbf{P P}_{\boldsymbol{n}}(19.0)$. Also note that the versatility of the MSM was further demonstrated by an accurate reproduction of the switching of the nature of the electronic transition in ${ }^{\mathbf{R} \mathbf{N}} \mathbf{P} \mathbf{P}_{\boldsymbol{n}}{ }^{+\bullet}$ due to shifting of the hole toward one end of the molecule.

In summary, we have demonstrated by combined experimental/DFT/theoretical modeling study of $N, N$-diisopropylaminocapped poly- $p$-phenylene (or donor-bridge-donor) wires ( $\left.{ }^{\mathbf{R} 2} \mathbf{P}_{\mathbf{P}} \mathbf{P}_{\boldsymbol{n}}\right)$ and by comparison with isoalkyl- and alkoxy-capped poly- $p$-phenylene wires that the extent of hole delocalization (or effective conjugation length) in $\boldsymbol{R P P}_{\boldsymbol{n}}{ }^{+\bullet}$ and the contrasting trends in evolution of oxidation energy are critically dependent on the energy gap between endcapped terminal and bridging $p$-phenylene units. This study also demonstrates the versatility of our Marcus-based MSM as a valuable tool for the guided design of the next-generation materials for longrange transport of charge. Moreover, the findings detailed herein will aid in the development of improved models for charge-transfer dynamics in donor-bridge-acceptor systems. ${ }^{43-46}$

The authors declare no competing financial interest.

\section{Acknowledgment}

We thank NSF (CHE-1508677) and NIH (R01-HL112639-04) for financial support, Dr. Sergey V. Lindeman for X-ray crystallography, and Professor S. A. Reid for helpful discussions. The calculations were performed on the highperformance computing cluster Père at Marquette University funded by NSF awards OCI-0923037 and CBET-0521602, and the Extreme Science and 
NOT THE PUBLISHED VERSION; this is the author's final, peer-reviewed manuscript. The published version may be accessed by following the link in the citation at the bottom of the page.

Engineering Discovery Environment (XSEDE) funded by NSF (TGCHE130101).

\section{References}

${ }^{1}$ Facchetti, A. Chem. Mater. 2011, 23, 733, DOI: 10.1021/cm102419z

${ }^{2}$ Li, C.; Liu, M.; Pschirer, N. G.; Baumgarten, M.; Müllen, K. Chem. Rev. 2010, 110, 6817, DOI: $10.1021 / \operatorname{cr} 100052 z$

${ }^{3}$ Lin, Y.; Zhan, X. Acc. Chem. Res. 2016, 49, 175, DOI: 10.1021/acs.accounts.5b00363

${ }^{4}$ Roncali, J.; Leriche, P.; Blanchard, P. Adv. Mater. 2014, 26, 3821, DOI: 10.1002/adma.201305999

${ }^{5}$ Carroll, R. L.; Gorman, C. B. Angew. Chem., Int. Ed. 2002, 41, 4378, DOI: 10.1002/1521-3773(20021202)41:23<4378: :AIDANIE4378>3.0.CO;2-A

6Talipov, M. R.; Boddeda, A.; Timerghazin, Q. K.; Rathore, R. J. Phys. Chem. C 2014, 118, 21400, DOI: $10.1021 /$ jp5082752

7Davis, W. B.; Svec, W. A.; Ratner, M. A.; Wasielewski, M. R. Nature 1998, 396, 60, DOI: $10.1038 / 23912$

${ }^{8}$ Heitzer, H. M.; Marks, T. J.; Ratner, M. A. J. Am. Chem. Soc. 2015, 137, 7189, DOI: $10.1021 /$ jacs.5b03301

9Heckmann, A.; Lambert, C. Angew. Chem., Int. Ed. 2012, 51, 326, DOI: 10.1002/anie.201100944

${ }^{10}$ Lambert, C.; Nöll, G.; Schelter, J. Nat. Mater. 2002, 1, 69, DOI: 10.1038/nmat706

${ }^{11}$ Lambert, C.; Amthor, S.; Schelter, J. J. Phys. Chem. A 2004, 108, 6474, DOI: $10.1021 / j p 048449 s$

12Talipov, M. R.; Hossain, M. M.; Boddeda, A.; Thakur, K.; Rathore, R. Org. Biomol. Chem. 2016, 14, 2961, DOI: 10.1039/C6OB00140H

${ }^{13}$ Lambert, C.; Nöll, G. J. Am. Chem. Soc. 1999, 121, 8434, DOI: $10.1021 /$ ja991264s

${ }^{14}$ Low, P. J.; Paterson, M. A. J.; Puschmann, H.; Goeta, A. E.; Howard, J. A. K.; Lambert, C.; Cherryman, J. C.; Tackley, D. R.; Leeming, S.; Brown, B. Chem. - Eur. J. 2004, 10, 83, DOI: 10.1002/chem.200305200

${ }^{15}$ Coropceanu, V.; Gruhn, N. E.; Barlow, S.; Lambert, C.; Durivage, J. C.; Bill, T. G.; Nöll, G.; Marder, S. R.; Brédas, J.-L. J. Am. Chem. Soc. 2004, 126, 2727, DOI: 10.1021/ja039263u

${ }^{16}$ Kaupp, M.; Renz, M.; Parthey, M.; Stolte, M.; Würthner, F.; Lambert, C. Phys. Chem. Chem. Phys. 2011, 13, 16973, DOI: 10.1039/c1cp21772k ${ }^{17}$ Sreenath, K.; Suneesh, C. V.; Kumar, V. K. R.; Gopidas, K. R. J. Org. Chem. 2008, 73, 3245, DOI: 10.1021/jo800349n 
NOT THE PUBLISHED VERSION; this is the author's final, peer-reviewed manuscript. The published version may be accessed by following the link in the citation at the bottom of the page.

${ }^{18}$ Venkataraman, L.; Klare, J. E.; Nuckolls, C.; Hybertsen, M. S.; Steigerwald, M. L. Nature 2006, 442, 904, DOI: 10.1038/nature05037

${ }^{19}$ Khan, F. A.; Wang, D.; Pemberton, B.; Talipov, M. R.; Rathore, R. J. Photochem. Photobiol., A 2016, 331, 153, DOI: 10.1016/j.jphotochem.2016.05.002

${ }^{20}$ Suzuki, A. Chem. Commun. (Cambridge, U. K.) 2005, 4759, DOI: 10.1039/b507375h

${ }^{21}$ Hassan, J.; Sévignon, M.; Gozzi, C.; Schulz, E.; Lemaire, M. Chem. Rev. 2002, 102, 1359, DOI: 10.1021/cr000664r

${ }^{22}$ Banerjee, M.; Shukla, R.; Rathore, R. J. Am. Chem. Soc. 2009, 131, 1780, DOI: $10.1021 /$ ja805102d

${ }^{23}$ Rathore, R.; Kochi, J. K. J. Org. Chem. 1995, 60, 4399, DOI: 10.1021/jo00119a017

${ }^{24}$ Dimethoxybenzene was used as a reference because $E_{0 \times 1}$ values of number of $\boldsymbol{R}^{\mathbf{2 N}} \mathbf{P} \mathbf{P}_{\boldsymbol{n}}$ were close to ferrocene.

${ }^{25}$ The second oxidation potentials ( $E_{0 \times 2}$ ) of ${ }^{\mathbf{R} 2 N} \mathbf{P} \mathbf{P}_{\boldsymbol{n}}$ remained nearly independent of $n\left(E_{\mathrm{ox} 2} \approx 0.27 \mathrm{~V}\right)$, and starting from $n=4$, they merged with the first oxidation wave.

${ }^{26}$ Rathore, R.; Burns, C. L.; Deselnicu, M. I. Org. Synth. 2005, 1, DOI: 10.1002/0471264229.0s082.01

${ }^{27}$ Talipov, M. R.; Boddeda, A.; Hossain, M. M.; Rathore, R. J. Phys. Org. Chem. 2016, 29, 227, DOI: 10.1002/poc.3523

${ }^{28}$ Further temperature lowering was not possible due to the precipitation of cation radical salts.

${ }^{29}$ The bond length changes (i.e., b1-b5) depicted in Figure 5D were based on the averages of equivalent bonds.

${ }^{30}$ Renz, M.; Theilacker, K.; Lambert, C.; Kaupp, M. J. Am. Chem. Soc. 2009, 131, 16292, DOI: $10.1021 /$ ja9070859

${ }^{31}$ Renz, M.; Kess, M.; Diedenhofen, M.; Klamt, A.; Kaupp, M. J. Chem. Theory Comput. 2012, 8, 4189, DOI: 10.1021/ct300545x

${ }^{32}$ Talipov, M. R.; Boddeda, A.; Lindeman, S. V.; Rathore, R. J. Phys. Chem. Lett. 2015, 6, 3373, DOI: 10.1021/acs.jpclett.5b01532

${ }^{33}$ Talipov, M. R.; Navale, T. S.; Rathore, R. Angew. Chem. 2015, 127, 14676, DOI: 10.1002 /ange.201506402

${ }^{34}$ Talipov, M. R.; Jasti, R.; Rathore, R. J. Am. Chem. Soc. 2015, 137, 14999, DOI: $10.1021 /$ jacs.5b09596

${ }^{35}$ The skewed hole distribution in ${ }^{\mathbf{R} 2 N} \mathbf{P P}_{3}{ }^{+\bullet}$, predicted by the DFT calculations, arises due to the sensitivity of hole distribution to a small variation in the amount of exact exchange in the density functional. See Figure S16 in the Supporting Information.

${ }^{36}$ Note that HOMO is symmetrically delocalized over both diisopropylaminocapped terminal units in all ${ }^{\mathbf{R} 2 \mathbf{N}} \mathbf{P} \mathbf{P}_{\boldsymbol{n}}$ (Figure S12A in the Supporting Information), while the spin/charge distribution is shifted toward one

Journal of the American Chemical Society, Vol 138, No. 50 (December 21, 2017): pg. 16337-16344. DOI. This article is (C) American Chemical Society and permission has been granted for this version to appear in e-Publications@Marquette. American Chemical Society does not grant permission for this article to be further copied/distributed or hosted elsewhere without the express permission from American Chemical Society. 
NOT THE PUBLISHED VERSION; this is the author's final, peer-reviewed manuscript. The published version may be accessed by following the link in the citation at the bottom of the page.

end in ${ }^{\mathbf{R} 2 \mathbf{N}} \mathbf{P P}_{\boldsymbol{n}}{ }^{+\bullet}$ with $n \geq 4$ due to the structural/solvent reorganization.

${ }^{37}$ The $\cos [n /(n+1)]$ coordinate originates from the tight-binding Hückel-like model based on the monomeric HOMOs, and it provides much better agreement with the experimental redox potentials and excitation energies of neutral and cation radicals than the reciprocal $1 / n$ coordinate, derived from a particle-in-a-box model and strictly speaking is not applicable to describe the properties of poly- $p$ phenylene wires; see: Torras, J.; Casanovas, J.; Alemán, C. J. Phys. Chem. A 2012, 116, 7571- 7583, DOI: 10.1021/jp303584b

${ }^{38}$ Note that the relationship between $\Delta \varepsilon$ and $H_{a b}$ was derived for the cases where $H_{a b} \gg \lambda$, as has been shown in the cases of a number of poly- $p$ phenylene wires, (6) see Section S9 in the Supporting Information.

${ }^{39}$ This finding is not surprising in the context of molecular orbital theory where an interaction between the orbitals of only identical energies affords maximal stabilization/destabilization of the resulting molecular orbitals (Figure S20 in the Supporting Information); see: Rauk, A. Orbital interaction theory of organic chemistry; Wiley-Interscience: New York, 2001.

${ }^{40}$ From the analytical expression for eigenvectors (eq S4 in the Supporting Information) it was shown that the hole would be evenly delocalized on all three units in a given ${ }^{\boldsymbol{R}} \mathbf{P} \mathbf{P}_{3}{ }^{+\bullet}$ when $\Delta \varepsilon_{\max } \lambda_{\max } H_{\mathrm{ab}}$ (which approximately corresponds to the case of $\left.{ }^{\boldsymbol{R} O} \mathbf{P P}_{3}{ }^{+\bullet}\right)$. If $\Delta \varepsilon \max \lambda_{\max } H_{a b}$ then charge will be more concentrated on the central unit (case of $\left.{ }^{\text {iA }} \mathbf{P P}_{3}{ }^{+\bullet}\right)$, while in the cases of $\Delta \varepsilon_{\max } \lambda_{\max } H_{\text {ab }}\left(\right.$ e.g., $\left.{ }^{\mathbf{R} 2} \mathbf{N} \mathbf{P P}_{3}{ }^{+\bullet}\right)$, the charge will be more depleted on the central unit.

${ }^{41}$ Talipov, M. R.; Ivanov, M. V.; Rathore, R. J. Phys. Chem. C 2016, 120, 6402, DOI: $10.1021 /$ acs.jpcc.6b00514

${ }^{42}$ The MSM predicts identical vertical excitation energies for all ${ }^{\mathbf{R}} \mathbf{P P}_{\mathbf{2}}{ }^{+\bullet}$ because a single value for electronic coupling $H_{\mathrm{ab}}$ was used for all three series of ${ }^{R} \mathbf{P P}_{\boldsymbol{n}}{ }^{+\bullet}$ with $\boldsymbol{R}=\boldsymbol{i A}, \boldsymbol{R O}, \boldsymbol{R 2} \mathbf{N}$. A detailed investigation of the role of varying electronic coupling $H_{\mathrm{ab}}$ in ${ }^{\boldsymbol{R}} \mathbf{P} \mathbf{P}_{\boldsymbol{n}}$ with different endcapping groups will be discussed in a future publication.

${ }^{43}$ Davis, W. B.; Wasielewski, M. R.; Ratner, M. A.; Mujica, V.; Nitzan, A. J. Phys. Chem. A 1997, 101, 6158, DOI: 10.1021/jp970909c

${ }^{44}$ Renger, T.; Marcus, R. A. J. Phys. Chem. A 2003, 107, 8404, DOI: 10.1021/jp026789c

${ }^{45}$ Barbara, P. F.; Meyer, T. J.; Ratner, M. A. J. Phys. Chem. 1996, 100, 13148, DOI: $10.1021 /$ jp9605663

${ }^{46}$ Davis, W. B.; Ratner, M. A.; Wasielewski, M. R. J. Am. Chem. Soc. 2001, 123, 7877, DOI: $10.1021 / \mathrm{ja0} 10330 \mathrm{z}$

Journal of the American Chemical Society, Vol 138, No. 50 (December 21, 2017): pg. 16337-16344. DOI. This article is (C) American Chemical Society and permission has been granted for this version to appear in e-Publications@Marquette. American Chemical Society does not grant permission for this article to be further copied/distributed or hosted elsewhere without the express permission from American Chemical Society. 
NOT THE PUBLISHED VERSION; this is the author's final, peer-reviewed manuscript. The published version may be accessed by following the link in the citation at the bottom of the page.

\section{Supporting Information}

The Supporting Information is available free of charge on the ACS Publications website at DOI: 10.1021/jacs.6b09209.

- Crystallographic data for $\mathrm{C}_{24} \mathrm{H}_{36} \mathrm{~N}_{2} \mathrm{SbCl}_{6}$ ( $\underline{\mathrm{CIF}}$ )

- Crystallographic data $\mathrm{C}_{24} \mathrm{H}_{36} \mathrm{~N}_{2}$ ( $\underline{\text { CIF }}$ )

- Details of synthesis and characterization data for various compounds including $\mathrm{X}$-ray crystallography, and computational details ( $\underline{\text { PDF }})$

Journal of the American Chemical Society, Vol 138, No. 50 (December 21, 2017): pg. 16337-16344. DOI. This article is (C) American Chemical Society and permission has been granted for this version to appear in e-Publications@Marquette. American Chemical Society does not grant permission for this article to be further copied/distributed or hosted elsewhere without the express permission from American Chemical Society. 